NBER WORKING PAPER SERIES

\title{
EXPLAINING ASSET BUBBLES IN JAPAN
}

Takatoshi Ito

Tokuo Iwaisako

Working Paper 5358

\section{NATIONAL BUREAU OF ECONOMIC RESEARCH \\ 1050 Massachusetts Avenue \\ Cambridge, MA 02138 \\ November 1995}

The authors thank John Campbell, Robert Flood, Shinichi Fukuda, James Stock, the participants of the NBER Japanese economy program meeting and Asset Pricing workshop at Harvard and anonymous referees for their helpful comments and suggestions on various drafts. Constructive comments by Ken West made the paper much improved. The authors also gratefully acknowledge David Scharfstein for calling attention to related studies in the literature and Rajeev Dehejia for his assistance in improving style of English. Assistance by Toshiyasu Izawa, Kiyoshi Matsubara, and Saibi Saito in collecting data is much appreciated. A major portion of the paper is based on the research conducted when the first author was a visiting scholar and the second author was a visiting graduate student at the Bank of Japan. This paper is part of NBER's research program in International Finance and Macroeconomics. Any opinions expressed are those of the authors and not those of any institutions with which the authors have been affiliated in the past or present, including the National Bureau of Economic Research.

() 1995 by Takatoshi Ito and Tokuo Iwaisako. All rights reserved. Short sections of text, not to exceed two paragraphs, may be quoted without explicit permission provided that full credit, including $(\mathcal{O}$ notice, is given to the source. 


\title{
EXPLAINING ASSET BUBBLES IN JAPAN
}

\begin{abstract}
This paper examines the stock and land price behaviors during the bubble economy period (the second half of the 1980s), paying considerable attention to the linkage of the two markets and the effects of monetary policy. In particular, we examine whether the booms in these asset prices can be justified by changes of the fundamental economic variables such as the interest rates or the growth of the real economy. A complex chain of events is needed to explain the process of asset price inflation and deflation. Our empirical results suggest (i) that the initial increases of asset prices are sown by a sharp increase in bank lending to real estate; (ii) that a considerable comovement between stock and land prices is consistent with a theory that emphasizes the relationship between the collateral value of land and cash flow for constrained firms; (iii) that although the real economy was doing well and the interest rates were still low, asset price increases from mid-1987 to mid-1989 cannot be fully justified by the movement of fundamentals alone; and (iv) the stock price increase in the second half of 1989 and the land price increase in 1990 is not explained by any asset pricing model based on fundamentals or rational bubbles.
\end{abstract}

Takatoshi Ito

Research Department International Monetary Fund 700 19th Street, NW Washington, DC 20431 and NBER
Tokuo Iwaisako Department of Economics Harvard University Cambridge, MA 02138 


\section{Introduction}

In the last ten years, the Japanese economy experienced a large fluctuations in asset prices, including stock prices, land prices, real estate in general, art paintings, and country (golf) club membership prices. In the second half of the 1980s, prices of stock and land prices doubled and tripled in a matter of a few years, although timings for sharp increases of various assets were not completely synchronized. ${ }^{1}$ Then, in the first half of the 1990s, many asset prices plummeted. In some cases, the gains in the second half of the 1980 s were completely offset by the losses in the first half of the 1990s. This asset price inflation and deflation not only affected fortunes of many corporations and individuals but caused serious problems in the macro economy, still challenging policy makers today. The relationship between macroeconomic policy and financial markets has drawn particular attention.

The experience of asset price inflation and deflation in Japan stimulated a large amount of research. We can identify three strands of research in the literature. First, the question whether the asset price inflation and deflation was caused by "fundamentals" or a "bubble" -price increases solely due to expectations of further increases -- has been asked by many financial economists: French and Poterba (1990) and Ueda (1990) on stock prices, and Ito (1993), Nishimura (1990), and Noguchi (1989) on land prices, to name a few. Those who regard the price increases as a bubble argue that the level and changes of asset prices cannot have been justified by theory of asset pricing: in particular, no changes in "fundamentals" correspond to the magnitude of fluctuations in stock and land prices. The crucial question here is whether asset pricing models where the effects of fundamentals are measured are reliable, since bubbles are typically inferred from the residuals of these models.

Second, the role of macroeconomic policy, especially monetary policy, in determining asset price movements has been examined, most often by looking at the movement of interest rates. A conventional wisdom states that monetary policy can be judged to have been lax from the 1987 to 1989 citing the historically low official discount rate.

Third, only a few papers --- Asako, et al. (1989) and Hamao and Hoshi (1991) --- have been written on the relationship between stock and land price movements. However, there is little rigorous theoretical and empirical investigation as on why and how the two kinds of asset prices influence each other. 
The contribution of this paper is three-fold, as attempts are made to make advance in each strand of research mentioned above. First, attempts are made to examine both a fundamentals story and a bubble story carefully. As mentioned above, "fundamentals" are defined usually by an asset pricing model, which depends on a particular set of assumptions. In this paper, we examine the robustness of such a model with respect to assumptions. A bubble model is simulated and calibrated, rather than just treated as residuals. Second, in judging monetary policy stance, we introduce a quantity variable, for example lending to real estate companies is introduced in addition to interest rates. This specification is consistent with a model which emphasizes the liquidity constraint and asymmetric information. Third, the connection between stock and land prices is a focus of this paper. There are two ways to look at the relationship, one way is to examine whether the process of the price dynamics for stocks and land has common fundamentals, including monetary conditions, and another to examine the direct mutual impact on each other. It will be obvious after the analysis that paying attention to only one of the prices seriously miss the important role of the process of price inflation and deflation in Japan in the last ten years.

The rest of the paper is organized as follows. Section two will analyze the land and stock price movements using simple time-series analysis. The third section will be devoted to an attempt to fit equations that can be implied from "fundamentals." It will be shown that the large fluctuations in asset prices cannot be explained by changes in variables that are commonly considered as fundamentals. Also rational bubbles are examined as an alternative explanation of the boom in the asset markets. In section four, within the multivariate VAR framework, the effect of monetary policy on the asset price fluctuations is examined. In section five, the effect of monetary policy on land prices through the bank lending channel is emphasized. Section six will summarize findings in the paper.

\section{Econometric Analysis}

\subsection{Data Description and Unit Root Tests}

The land prices and stock prices in Japan will be our primary asset prices to be examined. Although all pieces of land are heterogeneous and individual stock prices behave differently, the land price index and the stock price index will be dealt with in this paper in 
order to keep our macroeconomic analysis simple. We briefly describe the land and stock price indices to be used in the following sections.

LAND PRICE: An aggregate land price index in this paper is the nation-wide, average urban land price index (hereafter the land price index) tabulated semi-annually (March and September) by the Japan Real Estate Institute. ${ }^{2}$ This index is widely used in time series analysis, and dates back to September 1955. Other land price indices have shorter observation samples. 3 Since land prices which form the basis of the index are assessed by the assessors, instead of based on actual transactions prices, the index may not reflect the current market condition. 4

STOCK PRICE: The TOPIX, the value-weighted index of the first section of the Tokyo Stock Exchange, will be used for the stock price. The observations are taken from the last trading days of March and September in order to match the frequency of the land price index.

The basic statistics of land and stock prices measured by average excess returns, defined excess of the call rate, are reported in Table 2.1 (panels A and B). The frequency of data is every six month, but the reported numbers are annualized. The volatility, measured by unconditional variance, is far higher in stock prices. The time-series of land and stock price index levels are shown in Figures 2.1 and their changes are shown in Figure 2.2. Casual observations of these two figures suggest that stock returns lead land returns: Turning points after sharp increases come earlier in stock prices than land prices. The cross correlation of these two variables are shown in Table 2.1 (panel C.1). The highest correlation between the two asset prices occurs between stock prices at $t-2$ and land prices at $t$. Another difference in the behavior of the two asset price returns is in their autocorrelation structures: excess land returns have much higher persistence. Unconditional autocorrelation in Table 2.1 (panel C.2) suggest that if the land price increases by 10 percent in period $t$, then it will increase by 8 percent in period $\mathrm{t}+1$ (in 6 months).

As casually observed in Figure 2.1, the stock and land prices level seem to have unit roots. In order to check statistically the existence of unit root, the Dickey-Fuller (D-F) and the augmented D-F tests are conducted. Table 2.2 shows the result, where lag lengths on the right hand side are chosen using information criteria, namely AIC (Akaike Information Criterion) and 
SBIC (Shwarz's Bayesian Information Criterion) in the augmented D-F tests. The existence of unit root is not rejected for stock or land prices.

Further tests reassure us that taking first differences suffices to attain stationarity for the stock returns. The nominal land returns appear to allow for the possibility of being I(2), since the correlation of its inflation rate (the $\log$ difference) is very high. Testing the unit root hypothesis for various sub-samples suggests that the possibility of $\mathrm{I}(2)$ comes from the samples in the 1950s. If the first few years of the sample are excluded, we find the strong evidence of stationarity in the series of first difference. Or if excess returns are used instead of simple returns, we also find that the series is $\mathrm{I}(0)$. In the rest of this paper, we mainly use excess returns.

Table 2.3 shows the results of the variance ratio tests of nominal asset prices. The $z-$ statistics in the table is the heteroscedastic increments robust statistics derived by Lo and MacKinlay (1988). The test statistic follows an asymptotic, standard normal distribution. Given that we have relatively short sample, our conclusion based on this test is only tentative. The statistics suggest that the random walk hypothesis is not rejected for the stock price index, but is rejected for the land price index. The latter conclusion is due to high correlations in the land price inflation rate mentioned above.

\subsection{The Bivariate Vector-Autoregressions System (VAR) ${ }^{5}$}

In this section, the linkage between land and stock prices will be examined. The purpose of expanding a system to the bivariate system is two-fold. First, examining the two kinds of asset prices improves our chances of separating the bubble component from the fundamental values. Second, some theoretical explanation link stock prices to land prices and it is important to understand the process of bubble in the second half of the 1980s in Japan.

In order to judge whether bubbles were present, the theoretical, fundamental values have to be calculated. An asset is valued usually as a sum of discounted future profit streams from owning the asset. The discount factor depends on the market interest rate, and profit streams are heavily dependent on expectations for conditions of the economy in the future as well as of the specific asset market. Both the interest rate and the economy-wide conditions are common 
to land and stocks. By examining a bivariate system, the power of identifying economy-wide shocks may be increased by extracting a common movement in stock and land prices.

Natural linkages between stock prices and land prices emerge in the calculation of future profit streams. When land prices increase for any reason, a firm that happens to own a large amount of land enjoys an (unrealized) capital gains on its balance sheet. ${ }^{6}$ The unrealized capital gains signal the increase in future profit streams. Future profits will increase by realizing capital gains by selling the piece of land, utilizing land for high-yielding business (possibly diversifying its business), or borrowing more funds with the increased value of land collateral. The last option is particularly relevant for a liquidity-constrained firm with technology to generate income but having a difficulty convincing a bank. Hence an increase in land values logically results in an increase in stock prices. Conversely, when stock prices suddenly increase, land prices may be influenced by stock prices. An increase in stock prices may prompt firms (especially ones that are liquidity constrained) to use equity financing to raise funds for investment. Then these firms may purchase or lease lands in order to carry out fixed investment such as building factories and office spaces. The increased demand for land will push up the land prices. Thus, there are good reasons to believe stock and land price movements are correlated, but direction of causality cannot be determined in theory.

In order to gain insights on the nature of the land-stock relationship, a vectorautoregressions system (VAR), including stock and land prices, will be examined below. First, a bivariate system is examined. Since both the stock and land prices are I(1) variables, cointegration of stock and land prices is suspected. The t-test type unit root test of the residuals from spurious regressions (Phillips and Ouliaris, 1990) is employed. First, co-integration between concurrent asset prices is tested. Then, tests are conducted for co-integration between current land prices and lagged stock prices up to three lags. For all cases, we failed to reject the hypothesis that no cointegration exists between two asset prices at significance level of $5 \%$. We proceed with an understanding that cointegration between stock and land prices does not exist.

Table 2.4 presents results of bivariate VAR with excess stock and land returns from 1960:1 to 1993:1, with the sub sample results for the period after the first oil shock. Excess returns here are the returns only from capital gains over the short-term interest rate (Call-Tegata 
Rate). Using the nominal returns or the real returns gives the basically same results. The land returns are statistically explained by the past (one period lagged) stock and land returns. On the other hand, the current stock return is statistically independent of lagged land variables as well as its own lagged variables. The sub sample presents essentially the same results.

Figure 2.3 and 2.4 plot impulse responses to the shock in one variable in the bivariate VAR system. The orthognalization ordering for the plotted series is \{ESTOCK, ELAND\}. The qualitative result is robust for the change of ordering. The original simulated shocks are unit shocks in real returns of stock and land, and multiplier processes in level are calculated from impulse responses in returns. In the calculations for level, the initial shock (innovation) is assumed to be a one percent increase from the baseline level.

A one percent unexpected increase in stock prices causes a further stock price increase for two years but results in a permanent increase of 0.8 percent above the baseline. The one percent stock price increase results in a permanent increase of land prices by 0.6 percent land prices. A one percent unexpected increase in land prices strongly causes further land prices, resulting in a three percent land price increase. These findings are consistent with a popular observation that stock prices and land prices moves in concert. Since both asset prices respond to the same fundamentals, such as the interest rate and the economic growth rate (as a proxy to future cash flows), the comovement is not surprising. There are also other explanations which are consistent with the observed impulse response patterns.

The impulse responses of stock prices to the shock in land prices, however, appears to be counter-intuitive because they suggest negative long-run effects on stock prices. This apparent anomaly should be understood as a statistical relationship rather than a description of an economic causal relation. In the typical asset price boom, stock prices always staiistically leads land prices. Thus when land prices reached their peak, stock prices were already in their decline. The impulse response function captures the relationship as the negative effect of land return shock to stock return. There are two sources of leads and lags between two asset prices. The first source is, as mentioned in the description of land price index, that land price data does not reflect actual market prices accurately, so that responds to the shock only with delay. The second source is market imperfections in the real estate market, which will be discussed in 
section 6.

\section{Neoclassical Model and Bubbles}

\subsection{Neoclassical Asset Pricing Model}

In this section, a neoclassical model of asset price determination is introduced. In section 3.2, we extend this basic model to consider rational stochastic bubbles as an alternative explanation of the asset price boom in the second half of 1980 s. In section 3.3, some numerical examples are presented to understand how monetary policy could affect asset prices through the changes of real interest rates. We further explore how much of the price changes in the 1980s can be explained by the changes in "fundamentals" including reduction of the real interest rate.

In a standard asset pricing model, the current asset price is determined by the expected future stream of payoffs. We first recall the definition of an asset return $R_{t+1}$, and suppose that the real expected rate of return, $q_{t}$, is required, through arbitrage, for asset investment. Then,

$$
q_{t+1}=E_{t} R_{t+1}=E_{t}\left(\frac{P_{t+1}+D_{t+1}}{P_{t}}\right)-1
$$

where $P_{t}$ is the asset price, $D_{t}$ is the cash flow (dividend or rent) at time $t$. From this expression, we get an equation relating the current and next period asset price and cash flow:

$$
P_{t}=E_{t}\left(\frac{P_{t+1}+D_{t+1}}{1+q_{t+1}}\right)=\rho_{t+1} E_{t}\left(P_{t+1}+D_{t+1}\right)
$$

where $\rho$ is the expected discount factor defined by

$$
\rho_{t+1}=E_{t}\left[\frac{\left(P_{t+1}+D_{t+1}\right)}{\left(1+q_{t+1}\right)}\right] / E_{t}\left[P_{t+1}+D_{t+1}\right]
$$

Solving forward $\mathrm{K}$ period we have,

$$
P_{t}=E_{t} \sum_{i=1}^{K}\left(\prod_{j=1}^{i} \rho_{t+j}\right) D_{t+i}+E_{t}\left(\prod_{j=1}^{K} \rho_{t+j}\right) P_{t+K}
$$

By repeating the procedure, the following formula for asset price determination is derived: 


$$
P_{t}=E_{t} \sum_{i=1}^{\infty}\left(\prod_{j=1}^{i} \rho_{t+j}\right) D_{t+i}
$$

For now, we also assume the transversality condition (or "no Ponzi game" condition) so that "rational bubbles" are ruled out. (Rational bubbles will be discussed in section 3.2):

$$
\lim _{K \rightarrow \infty} E_{t} \sum_{i=1}^{K}\left(\prod_{j=1}^{i} \rho_{t+j}\right) D_{t+i}=0 .
$$

Expression (3.3) is a very general formula for asset price determination. In addition, we adopt the following common assumptions in the literature.

(A.1) Constant discount factor: $\rho=\rho_{\mathrm{t}+1}=\rho_{\mathrm{t}+2}=\ldots \ldots \ldots=\rho_{\mathrm{t}+\mathrm{I}}$ Further, we assume $q$ is equal to constant risk-free interest rate, i.e., $\rho^{-1}=1+r_{t}=1+r \quad$ for all $t$.

(A.2) Constant dividend (or rent) growth rate: $D_{t+1}=(1+g) D_{t} \quad$ for all $t$, and $g<r$.

The assumption (A.1) implies the risk neutrality of investors. In reality, the expected returns to risky assets should include risk premium. By assuming (A.1), (A.2), and perfect foresight, the expression (3.3) is reduced to the following heuristic expression, which is often called the Gordon valuation model in the finance literature:

$$
P_{t}=D_{t} /(r-g)
$$

This relationship is easy to verify. 7

As clearly seen from the right hand side of the above expression, asset price is quite sensitive to a small change in " $r$ " and " $g$ ". Rearranging (3.5) we have the following expression for the dividend (or rent) /price ratio.

$$
D_{t} / P_{t}=r-g
$$


The casual evidence cited in the preceding section suggests that equation (3.5) likely holds in the U.S. stock markets. But it hardly holds for the Japanese stock or land markets, since the dividend/price ratio fluctuated wildly, or drifted up so much. However, "g" could be understood as the growth rate of earning of the firm, in the sense that it reflects the future returns from both dividends and capital gains.

\subsection{Simulation with Interest Rate Changes}

Next, let us turn to the changes in fundamentals as the cause of asset price boom and bust in the second half of the 1980s and in the beginning of the 1990s. The changes of fundamentals are represented by the reduction of discount rate " $r$ " and the increase of growth rate of dividends (or earning in more general) "g." Many economists (e.g. Japan Security Analysis Institute, 1988) argued that it was quite natural to see the asset price increase, since the interest rate was sharply lowered from 1985 to 1987 . The official discount rate remained at a record low level of $2.5 \%$ from 1987 to 1989 . For example, if the required rate of return is 6 percent, while the dividend growth is 3 percent, then the P/D ratio is 33; while the decrease in the required rate of return (interest rate) to 5 percent makes the $\mathrm{P} / \mathrm{D}$ ratio to increase to 50 .

Thus a small increase in " $r$ " causes a large change in " $P$." The two percent point decrease in the interest rate triples the price. Hence, all the wild fluctuation in stock and land prices in the second half of the 1980s can be explained by the changes in " $r$," many argued.

However, this argument is not correct, unless all participants thought that the interest rate change is a "once-and-for-all" type change, that is, a permanent change to a new lower level from a higher level. Since the interest rates go up and down depending on the stage of business cycles, (A.1) does not hold true in its purest form. Suppose, instead, a more realistic situation that the change in the interest rate or the growth of dividend is perceived as "temporary." Now, let us consider the temporary decrease of $r$ from $6 \%$ to $5 \%$ or to $4 \%$. It is assumed to be the case that $\mathrm{g}=3 \%$, and the interest rate will return to $6 \%$ after $\mathrm{K}$ periods. Admittedly, the length of time $(\mathrm{K})$ where the new interest rate level is in place, or the level itself in the future, is difficult to quantify since they are in the minds of the market participants.

However, still some simple observations are possible. First, with rational expectations, 
it is justified to use ex post real interest rates in calculating the effect of the low interest rate on fundamentals. Figure 3.1 shows the difference of ex post " $\mathrm{g}$ " and " $r$ " and the Nikkei index. 8 Stock prices today reflect the expectation of future changes of fundamentals as well as the fundamentals today, so the entire future paths of " $r$ " and " $g$ " from tomorrow give the effects to the asset price today. It seems impossible to offer a rational explanation of the asset price inflations in the second half of the 1980s by the changes in fundamentals, namely " $\mathrm{r}$ " and " $\mathrm{g}$," unless lower interest rates were expected to continue forever.

To see this point, let us do some calculations. From the period from the first oil shock of 1973 to 1993, real stock price growth rate was on average 6-6.5\% annually. So assume $\mathrm{g}$ $=6.5 \%$ in 1985 , though this is obviously much higher than the average growth rate of actual dividends in this period. ${ }^{9}$ Although the Japanese economy was suffering from the deflationary effect of the sharp appreciation of the yen against dollar from the first quarter of 1986 to the first half of 1987, it was temporal. So we further assume that $\mathrm{g}$ was unchanged (nonincreasing). TOPIX was approximately 1000, 1265, and 1870, respectively in March 1985, 1986, and 1987. So from March 1985 to March 1986, the stock price increased 26.5\%. If " $r$ " had been constant, the appreciation of stock prices must have been $6.5 \%$ plus some error, so that TOPIX would be 1065 . Thus the remaining $3 / 4(=1-6.5 \% / 26.5 \%=0.755)$ of the price increase has to be explained by the reduction of interest rate. In order to make the story simple, let us assume that all further stock price increases took place at the end of this period. Then we have to consider the change of the future interest rate path which would cause a $15 \%-20 \%$ $(1265 / 1065-1=18.8 \%)$ increase of the stock prices today. ${ }^{10}$ This means real interest rate has to go down by $2 \%$ for 11 years, or by $3 \%$ for 7 years. Considering the two year period of from March 1985 to March 1987, more than 4/5 of 87\% price increase must be explained by the reduction of real interest rate, which means $3 \%$ reduction of the interest rate for more than 20 years. Even if we change the starting point to March 1986, a perception of a $3 \%$ reduction for 13 years is required in order to explain additional $40 \%$ stock price appreciation from March 1986 to March 1987. On the other hand, the fall of interest rates from the first quarter of 1985 to the first quarter of 1987 was around $3 \%$, and the nominal interest rates recorded their lowest levels in May or June of 1987 during this monetary expansion period, while the inflation rate 
was no more than $0.5 \%$ per year.

Those who still believe that the asset pricing model should be able to explain price movements may argue that " $g$ " as well as " $r$ " have changed. As noted above, the perception of growth was not particularly great after the sharp (60\% percent) yen appreciation from September 1985 to August 1986. Although strong growth resumed in 1987, it is highly debatable that a long term trend of " $\mathrm{g}$ " has changed at around 1986-87 and the investors had acknowledged that change.

One support for a fundamentals story comes from the pattern of land price increases from 1986 to 1988. (See Ito, 1992, for discussions below.) The initial increase in price occurred in commercial property in central part of Tokyo. Then it spilled over to residential, first-tier suburbs of Tokyo, before it spread to neighboring prefectures and cities of Tokyo and other large cities such as Osaka and Nagoya in one year. The initial increase in land prices in the central Tokyo coincided with the increased demand for commercial properties due to increased role of the Tokyo financial center.

Next, we consider the further increase of the stock prices after Black Monday. In March 1988, when Tokyo market had fully recovered the level just before Black Monday, TOPIX was 2145. By the end of year 1989 , TOPIX rose to 2880 , that is approximately $40 \%$ increase of TOPIX is observed in two years of 1988 and 1989. First, the real interest rate was already at a record low level in 1987, and became even lower in 1988 and 1989. However, this is mainly because the inflation rate measured by CPI began to rise as the real economy experienced the big boom. So it is natural to assume that future monetary tightening by the Bank of Japan had been expected, so that at least no further prolonged interest rate decline should have been expected. So let us assume " $r$ " was expected to be unchanged in this period. Then, $(1.065)^{2}$ $=13.5 \%$ increase in two years would be expected, so that TOPIX was supposed to be around 2350. This time, remaining $65-70 \%$ of the stock price increase in this period has to be explained by the change of " $\mathrm{g}$ " alone. In the context of our thought experiment, this implies that we have to consider the change of the future path of " $\mathrm{g}$ " that would cause $20-25 \%$ asset price increase today. (For example, if all further stock price increase due to the change of " $\mathrm{g}$ " at the end of this period, $2880 / 2350-1=22.55 \%$.) This corresponds to the $2 \%$ increase change of " $\mathrm{g}$ " more than ten years. It is true that the real economy was in the big boom from 
1988 to 1990 , so that this story might be rationalized that if it was unforeseen change of "g." But, it is too hard to assume that this boom is totally unexpected at the beginning of 1988 . And the recovery from Black Monday cannot be justified if it is not expected. Also, the growth rate of dividend was stagnated in 1988 and 1989 compared with the period of 1985 to Black Monday in October 1987. Overall, it is safe to say that further increase of stock prices in this period cannot be fully justified by the change of fundamentals. Furthermore, it is even harder to justify the stock price increase in 1988-1989 compared with the period of 1985 to right before Black Monday. The stock prices might have been too low in 1985, but apparently the prices were already very high at the beginning of 1988 .

\subsection{Rational Stochastic Bubbles}

Some researchers (for example, Asako et.al., 1990, Asako, 1992) tried to explain the boom and bust of Japanese asset prices using a model of rational stochastic bubbles. ${ }^{11}$ The rational stochastic bubble model can explain why the asset price exceeds the price level determined by the fundamentals. Rational bubbles are modeled by adding the "bubble" term to (3.3), and assume constant discount factor (A.1) (i.e., constant expected returns).

$$
P_{t}=E_{t} \sum_{i=1}^{\infty}\left(\frac{1}{1+r}\right)^{i} D_{t+i}+b_{t}
$$

As long as $(1+r) b_{t}=E_{t} b_{t+1}$, this equation satisfies the arbitrage condition (3.1). The simplest case is the deterministic bubble which implies $(1+r) b_{t}=b_{t+1} \cdot 12$ In order to make the model more realistic and to incorporate inflation and deflation of asset prices, $b_{t}$ can be modified to be stochastic, which is first developed by Blanchard (1979) and Blanchard and Watson (1982). For example, Blanchard and Watson suggested the following specification of the stochastic bubble, where $e_{t+1}$ is the white noise:

$$
\begin{aligned}
b_{t+1}=\left(\frac{1+r}{p}\right) b_{t}+e_{t+1} & \text { with prob. } p \\
=e_{t+1} & \text { with prob. 1-p }
\end{aligned}
$$

Empirical testing of the "bubble" in asset prices is closely related with the volatility tests 
which LeRoy and Porter (1981) and Shiller (1981) started more than a decade ago. In this empirical literature, excess volatility of asset prices are identified as the residuals from actual price minus "fundamentals." Thus the stock market volatility debate is reduced to the identification problem of the "fundamentals." One approach is, like Shiller's original work, to use ex post dividend payout in the present-value relationship (3.3), to obtain the approximate fundamental asset prices. Another approach is to use the time series model of dividends, for example West (1987). The econometric methods used in initial papers have been extensively criticized, but recent work which avoids these problems still finds excess volatility (see, Flood and Hodrick, 1990, Campbell, Lo, and MacKinlay chap.7, 1994, for survey). However, recently the controversy has diminished. Although volatility tests have attracted considerable attention, as Summers (1991) noted "it is hard to identify people whose mind has been durably changed by this research." This is mainly because the finance profession is convinced that the expected stock returns are time-varying, so the predictability of the returns has become the focus of attention among researchers from the second half of the 1980s. ${ }^{13}$

In small sample, usual Shiller-type volatility tests cannot distinguish rational bubbles from the composite hypothesis that stock prices are more volatile than the justified by rational forecasts of future dividends. ${ }^{14}$ So the reason for the excess volatility or the apparent deviation from the fundamentals, if it is found, does not have to be rational bubbles. In order to distinguish empirically rational bubbles from other irrational models of excess volatility, we have to find some empirical implication which is unique about the model of rational bubbles. The rational stochastic bubble model implies an explosive path of asset price. As the crash probability of the bubble increases, the price path of the bubble asset must be more and more explosive and steeper. There is little evidence of such explosive behaviors in both stock and land prices, and in any stock market in developed countries for the sufficiently long period which could be compared with the bubble economy period in Japan. Asako et al. (1990) try to identify rational bubbles in Japanese stock price index by distinguishing the explosive price path, but they found very limited evidence. They concluded that the source of the asset price boom in Japan was more likely to be irrational bubbles rather than rational bubbles. However, modeling and estimating of stochastic bubbles is not sophisticated in Asako et al. (1990) or any other work in the literature. 
Below, we attempt a direct calculation of crash probability of stochastic bubble, though admittedly simplistic, in order to see how likely the reality was caused by stochastic bubbles. Suppose that in March 1985, the stock price index, TOPIX, was exactly at the "fundamental" value, and that after March 1985, the fundamental value grew at the rate of $6.5 \%$ per year (as shown in a thick solid line in Figure 3.2). Actually, the assumption of $6.5 \%$ is consistent with the increase calculated by the simple time trend. Then the realized stock price is above the fundamental value by $117 \%$ in March 1986 , by $178 \%$ in September 1987 , and by $200 \%$ in December 1989. Provided that these values are correct, $p$, the probability that the bubble will last in the following period can be calculated using (3.8).

$$
p=(1+r)\left(\frac{b_{t}}{b_{t+x}}\right)^{-x}
$$

If we use the value in March 1986 as $b_{t}$ (the initial bubble) and the value in September 1987 (right before the October crash) as $b_{t+x}, p$ will be approximately 0.81 for quarterly data. This sample path is shown as "bubble-1" in figure 3.2. Given that today's stock price includes some bubble component, the bubble will last another three months with the probability of $81 \%$. To support this sample path of "bubble-1" in figure 3.2, the bubble has to last 18 to 21 months. So it means such a sample path will hold that long with the probability of $0.81^{7}=18.5 \%$.

If we use the value in December 1989 (the highest price level and the largest deviation from the fundamentals) as $b_{t+x}, p$ will be approximately 0.925 . This is "bubble-2" in figure 3.2. In the "bubble-2" case, the bubble has to last 42 to 45 months. Then the probability that bubble- 2 can persist is $26.5 \%$.

Actual data seems to fit better the sample path in the first case. Finally, if we assume that the sample path switched from "bubble-1" to "bubble-2" after the October crash in 1987, such a sample path will sustain with the probability approximately 7\% ("bubble-3"). The calculation of $p$ is sensitive to the choice of $b_{t}$ and $b_{t+x}$, and the above values of $p$ should be understood as the maximum of the possible values. So the probabilities that the bubble lasts along with the sample paths are also the largest of the possible values. For example, if the value at December 1985 is used as the initial condition $b_{t}$, the probability that "bubble-1" can be 
sustained will be $6 \%$, so the "bubble-3" will be about $2.5 \%$.

Some researchers may observe that those probabilities are high enough so that the reality may be consistent with the stochastic bubble model, while others may think otherwise. But, even with "rational stochastic bubbles," it is very hard to explain the boom in the Japanese stock market in the second half of 1980s. Especially, the behavior of stock price index after October 1987 hardly fits the rational bubble explanation.

\subsection{Term Structure}

As discussed in section 3.2, one possible explanation for the sharp increase in asset prices from 1986 to 1989 is that people made irrational expectations about future real interest rates, since if the decrease of the real interest rate was permanent, this explanation seems to fits the behavior of asset prices in 1980s. Asset prices should increase sharply in 1986-1987, and then stay at the high level. On the other hand, rational bubbles which was discussed in the previous sub section predicts that asset price would take an explosive path which is not the case. The actual data in the last ten years can be simulated better with the irrational expectations.

This possibility can be inferred from the term structure of interest rates. The literature of the term structure of interest rates assumes rational expectations in testing the expectations hypothesis. Usually, the pure form of expectations theory is rejected statistically. However, Froot (1989) argued that the expectations hypothesis fits the data better if expectations are taken from surveys. ${ }^{15}$ So by giving up rational expectations assumption, the market expectation of future short term interest rates can be inferred from the term structure. Figure 3.3 shows the path of real interest rate, official discount rate, and the term structure. ${ }^{16}$ First, the sharp increase of the short-term rate right after the Plaza accord created the large negative spread in this period. After that, from the middle of 1986 to the middle of 1989 , no significant pattern of the term structure can be observed from the graph. Campbell and Hamao (1993) explain it as the result of the change in the behavior of the short-term interest rates due to the change in the conduct of monetary policy in this period. The short-term interest rate became more volatile and less predictable in the second half of 1980 s compared with early 1980 s. Responding to the tight monetary policy from the middle of 1989 , at first, the long-term rate did not change. So it seemed like the market took this policy change was only temporary. This may be one of the reasons that the stock prices continued to rise until the very end of 1989. Then the market 
is convinced to take the tightening of monetary policy seriously, so that the long-term rate caught up the short-term rate. From 1991, the term structure has behaved in a typical manner: the short term was higher than the long-term in the period of monetary contraction, and lower when the official discount rate was decreasing.

Figure 3.4 is the path of the real interest rates in this period. The real interest rates were low from 1987 to 1989 , and from the above discussion of the term structure, it is suspected that the market anticipated that it was going to stay at low level when tight monetary policy began in 1989.

\subsection{Synthesis and Remaining Questions}

In sum, the discussions in this section can be put together as follows. In view of neoclassical model and its expansion to include bubbles, asset price inflation from 1985 to 1989 , and subsequent deflation, were caused by multiple factors. The initial shock in 1985 and 1986 may have belonged to "fundamentals," such as an increased demand for the Tokyo commercial property and higher productivity increase in Japanese industries (the increase in " $\mathrm{g}$ ") and expansionary monetary policy (the decrease in " $r$ ").

However, there is a limit to the fundamentals story. Although the initial shock may have been land "fundamentals" in Tokyo, followed by monetary policy fundamentals, it is difficult to put together for different stages of asset price inflation. From 1985 to the end of 1986, economic growth prospects were weak, but asset prices were already rising. (A hardcore believer of fundamentals might justify the increase in asset prices at this period by invoking rational expectations on the expansion of the economy in the following years, but then it is difficult to justify the failure in foreseeing the crash in the beginning of the 1990s.) From 1986 to 1987 , both the interest rate movement and growth movement do indicate that asset prices should increase. The direction is right. However, the magnitude of increases in stock and land prices is difficult to justify from the magnitude of decrease in " $\mathrm{r}$ " and/or increase in " $\mathrm{g}$," unless the changes were perceived, wrongly, as permanent (say, persistent for the coming ten years or so).

From 1987 to early 1989, there was no fundamentals news significant enough to explain further stock and land prices. Although real interest rates were still decreasing, that was coming 
from higher inflation, which should have prompted investors to anticipate coming nominal interest hikes.

From early 1989 to the end of 1989 for stock prices, and the end of 1990 for land prices, there is little evidence which would have justified the further rises in stock and land prices in the fundamentals model framework.

With these limitations in mind, some particular form of a stochastic bubble model was simulated. The model was designed to calculate the crash probability from actual rises in asset prices. Combining the fundamentals and bubbles stories together, one could argue that the first part of the asset price rises, maybe until late 1987, was mostly explained by fundamentals model with overly optimistic expectations on the part of investors. But sometime after that, the asset market turned into bubbles. Once the bubble seed was sown (the beginning of stochastic bubbles), then it proceeded to get larger, purely on expectations of further bubbles, until the crash came in the early 1990s.

However, even with this ad hoc integration of fundamentals and bubbles, questions remain. In particular, macroeconomic policy during the period in question may not be adequately captured by the call market interest rate. Another important question of the relationship between the stock and land price increases are not really addressed in this section. The following sections attempt to answer these questions.

\section{Macro-variables and Monetary Policy}

\subsection{Multivariate VAR}

In this section, we extend our VAR system in section 2.2 to include macro-variables, and consider the effect of monetary policy on asset prices. Later, we employ the framework for variance decomposition recently developed by John Campbell (Campbell, 1991, Campbell and Ammer, 1993) to further investigate the nature of asset price movements in Japan.

New VAR system consists of the following variables: Excess Stock Returns (ESTOCK), Excess Land Returns (ELAND), Real Interest Rate (RRATE), the First Difference of Interest Rate (ARATE), the Growth Rate of Bank Loans to the Real Estate Sector (GLOAN), and the Log of Earning-Price Ratio (LEPR). We find the growth rate of bank loans to the real estate sector (GLOAN) has high explanatory power for LAND. About details of GLOAN, see the 
section 3. We estimated the full sample, 1969:2-1993:1, which is constrained by the availability of GLOAN series, and the "pre-bubble" sub sample, 1969:2-1993:1. Dividing the samples at 1985:1 might be more informative, but we have too few observations to draw the conclusions using such sub samples.

Another variable that has to be explained is LEPR (the log of the earning-price ratio). We used LEPR as the "fundamental" variable, instead of the log of the dividend-price ratio in Campbell's papers because the dividend-price ratio in the Japanese system behaves quite differently from the U.S. ${ }^{17}$ In Japan, the dividend-price ratio has been steadily declining over the sample period, even before the "bubble-era," and fluctuation around the declining trend does not seem to signal anything. Furthermore, we found unit roots in both the dividend-price ratio and the $\log$ dividend-price ratio, though both of them were significant in explaining stock returns. This a quite different behavior of aggregate dividends in Japan is perhaps a subject for another paper. The appendix at the end of this paper provides our partial evaluation of this problem. Overall, we decided to use the earning-price ratio rather than the dividend-price ratio in our system. However, LEPR itself is not free from the unit root problem. We reject unit root in LEPR series for before 1985:1, but cannot reject for the full sample. Ferson and Harvey(1994) studied various fundamental variables in the various national markets. From their study (especially figure 2A.1-4 in their paper), we suspect that unit roots cannot be rejected for any other "fundamental" variables for the period including 1985:1-1991:12. But, the "prebubble" behaviors of the "fundamental" variables in Japanese market other than the dividendprice ratio is quite similar to in other countries. This fact would be the support for the view that the boom in the stock prices from 1985 to 1990 cannot be rationalized by the changes in the fundamentals.

Tables 4.1 and 4.2 show the results of multivariate VAR. From these tables, the followings are observed. First, apparently monetary policy does affect the asset prices. The result that ESTOCK Granger-cause ELAND in bivariate VAR in section 2 should be interpreted as the result of the different transmission mechanisms of monetary policy to the different asset prices. GLOAN is a very important factor in predicting both stock and land excess returns. ARATE Granger-causes the increase of excess asset return only in ESTOCK regressions. This implies the bank lending channel is more important than the direct effect of the interest rate 
changes for the land price changes. Also compared with the pre-bubble sub sample, GLOAN is more significant in ELAND in regression, which suggests the credit channel was especially important in the bubble-era. Second, as we found in the bivariate system, the lagged ESTOCK and ELAND explains current ELAND. Especially, lagged ELAND is very strong in explaining current ELAND, which implies strong autocorrelations in ELAND.

\subsection{Variance Decomposition}

Next, we use the variance decomposition for asset returns proposed by Campbell (1991) and Campbell and Ammer (1993) to further investigate our VAR system. ${ }^{18}$ Campbell's basic framework is the following accounting equation for the (unexpected) asset excess return: 19

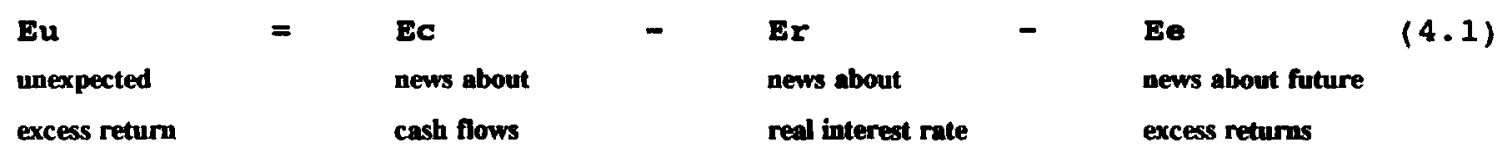

Note that Equation (2.1) is not a behavioral model, but a dynamic accounting identity that imposes internal consistency on expectations of the (representative) investor. This identity implies the following covariance relationship;

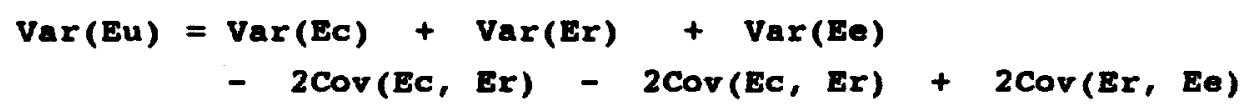

In practice, Eu is estimated as the residuals of the excess return regression. Er and Ee are calculated from the residuals of the excess return and the real interest rate regressions using VAR coefficients. And $\mathrm{Ec}$ is equal to $(\mathrm{Er}+\mathrm{Ee}+\mathrm{Eu})$ by definition.

The early volatility test papers (LeRoy and Porter, 1981, Shiller, 1981) are criticized because of the difficulty in modeling and estimating dividends' time series process. This point is emphasized by Marsh and Merton (1986). The same criticism applies equally to VAR systems including dividends. The key insight of Campbell's approach is that, by using of equation (2.1), the difficulty in estimating the stochastic processes of cash flows (dividends or rents) can be avoided.

One difficulty in carrying out the Campbell type variance decomposition is the choice of 
discount factor $\rho$ for land. ${ }^{20}$ Denoting the dividend/price ratio (or the rent/price ratio for real estates) by $D / P, \rho$ is equal to $(1+D / P)^{-1}$. Ueda (1992) estimated of the rent/price ratio based on micro data of real estate companies' revenues in rents and real estate assets. According to Ueda, the average $P / D$ ratio for $1970-80$ was 19.3 (i.e., the annual $D / P=5.18 \%$ ); the $P / D$ for $1980-85$ was $15.3(\mathrm{D} / \mathrm{P}=6.54 \%)$; and the $\mathrm{P} / \mathrm{D}$ for $1986-89$ was $31.5(\mathrm{D} / \mathrm{P}=3.17 \%)$. Ito and Nosse-Hirono (1993), using advertized prices and rents in the trade magazine, calculated the D/P ratio in the Tokyo apartment market for the 1980s from micro data. It has fluctuated between 17 and 32, so their study is consistent with Ueda's estimation. On the other hand, the annual D/P of stocks were $1.71 \%$ in $1980,0.45 \%$ in 1989 (that was the peak of the boom), and $0.74 \%$ in 1992.21

In the empirical study below, we use $\rho=0.993$, which is implied by the dividend/price ratio of stocks, for the variance decompositions of both stock and land returns. Although the choice of $\rho$ would not change the result dramatically, we have to bear in mind a potential problem of discount factor in the following discussions.

Table 4.3 shows the result of variance decompositions. Our results greatly differ from Campbell and Ammer (1993). Campbell and Ammer showed that most of the unexpected excess returns are explained by news about future excess returns and that the share of dividend innovations is less than $20 \%$. Our results, shown in table 4.3 indicate that for the Japanese stocks, the news about future dividends is the most important factor. However, considering the negligible level of dividends in Japan, it is puzzling to find the variance of news about future dividends being so large.

One explanation is the difference in the data frequency. Capmbell and Ammer used the monthly frequency, while the present paper uses the six-month frequency. As Campbell and Ammer themselves noted, variation in expected returns cause transitionary variation in stock prices while dividend news cause permanent variation. So dividend news becomes more important for longer time intervals (Campbell and Ammer, p.22). In other word, by using the low frequency data, the important information about the short-term mean reverting behavior of stock prices is averaged out.

The comparison of the full sample estimation and the pre-bubble sub-sample $(-85: 1)$ gives 
some interesting information about stock returns. First, the unconditional variance of unexpected excess returns Eu (= the residuals from the ESTOCK regression) is much larger in the full sample than in the pre-bubble sub sample. The ESTOCK regressions in Table 4.1 also tells us that the fitting measured by corrected $\mathrm{R}^{2}(\mathrm{R}$ Bar $* * 2)$ is much better for the pre-bubble sub sample. Finally, in the earlier version of our paper, the parameter stabilities in the asset return regressions are examined using the rolling Chow test. There was no significant structural break found, but the likelihood ratio statistics is highest at 1985:01 in the ESTOCK regression. All these evidences suggest that the mechanism that determines the asset returns changed after 1985. On the other hand, if we look at the shares of variables in the variance decomposition, in the pre-bubble sub-sample, dividend news and interest news are more important, while expected return news is less. Before the bubble period, fundamentals, such as interest rates and dividends, have contributed to explaining stock and land price behaviors, while after 1985:2, factors other than fundamentals becomes relatively more important. This is consistent with our view in section 3 that the stock price boom in the second half of 1980s cannot be justified by the changes of "fundamentals."

Results of the land returns regressions, also in Table 4.3, are even more dramatic. The sum of variances of news about future rents exceeds the variance of excess returns. This is due to the high predictability (small variance of Eu) and the high auto-correlations of excess returns. Note that the variance of news on future excess returns (Ee) is larger than the variance of unexpected excess returns $(\mathrm{Eu})$, and $\mathrm{Ee}$ and $\mathrm{Eu}$ are highly correlated. Our VAR system is like an investor using only very recent history (one lag), and forecating future by linear projection. So when the land price increases today, the investor (VAR system) predicts the further increase of excess returns in near future (Figure 4.1). Within the linear projection framework, this result implies the explosive or unstable path of excess land returns. This is another way to describe the predictability and autocorrelations of the land returns. As will be discussed in the next section, the predictability may not necessarily imply the inefficiency of the land market or unexploited arbitrage opportunities. So the expectation accounting equation, Equation (4.1), which is based on an assumption of the perfect, frictionless capital market, may be failing to capture the true relationship of land returns and other variables. Too large a share of Ec variance is just a consequence of this fact. 


\section{Lending Constraints and Transaction Costs Models}

The characteristic of land returns described in the previous sections leads us to the necessity of the model which can explain their autocorrelations and predictability. In this section, particular kinds of non-neoclassical models which pay special attentions to the nature of trade in real estate market are explained, and attempts will be made to evaluate them empirically.

As we have seen, the neoclassical model of asset price determination needs a strong assumption on future information, in that future dividends (rents) are assumed to be known (or that at least their probability distribution is known to all participants, and that investors are assumed to be risk-neutral). Bubbles (to be explained in details in the next section) are also precluded by assumption. The monetary policy in the neoclassical model is represented solely by the level of interest rate, which is relevant as the discount factor.

Casual evidence suggests that quantity variables like bank lending are relevant in the process of asset price inflation. In the perfect neoclassical world, price immediately jumps to the right level responding to the news about the fundamentals, so that, in the extreme case, transactions (changing ownership) not necessarily takes place, while price variables summarize the information adequately. However, in the real world, the price increase usually takes place with heavy transactions, reflecting heterogeneous information or expectations among investors. Moreover, payments cannot be readily arranged by investors with liquidity constraints unless investors' information and expectation are shared by banks too. Then, it matters how much banks are willing to finance the projects which require acquisition of land or stocks.

Models to be explored in this section will be similar to those that emphasize the effect of the firm's credit condition on its investments (Fazzari, Hubbard, and Petersen (1988), Hoshi, Kashyap, and Scharfstein (1991), and Kashyap, Stein, and Wilcox (1993)). These models explain how investment could be dependent on bank lending. Firms may be liquidity constrained due to the asymmetric information, which means that the firm's credit worthiness becomes important when the firm is liquidity constrained due to potential lenders not being convinced of the quality of projects. Hence, if there are some ways to get around this asymmetric information 
problem, investment will be higher. For example, in Hoshi, Kashyap, and Scharfstein, the information problem is assumed to be alleviated among the enterprise group (keiretsu) firms. If the firm can put up some collateral or any other kind of front-loading bonds, then it also serve to solve the asymmetric information problem.

There are two ways to describe the importance of collateral. The first one is based on asymmetric information, emphasized in Stiglitz and Weiss (1981). Suppose that there are two types of borrowers, good and bad, and lenders cannot differentiate between the two. A lending rate increase will squeeze out more good borrowers than bad. So an optimal solution when lenders cannot verify the quality of borrowers may result in credit rationing. Suppose that asset price inflation (either stock or land price) takes place, and that the borrowers hold some assets to be used as collateral. Then the increase of collateral value of the borrowers' asset will enhance credit lines for lending, and consequently, the net worth of the credit-constrained borrower. This will further increase the stock price of the borrower, and the collateral value of (other) firms' assets. The second approach to the use of collateral is based on the enforceability of contract and the possibility of renegotiation, often known as the "incomplete contracts" approach to financial contracting. Even in the perfect information world, it may be difficult to enforce the contract. When we consider the possibility of renegotiating contracts for holdup and/or deducing debt payments in the case that the borrower firms business went wrong, lenders want collateral at the first place. Thus the bank lending will be an increasing function of collateral, and the story after that is exactly same as the case of information asymmetry.

Scharfstein (1994) presented a model of multiple equilibria, in which depending on the people's expectation either "the high collateral price - the low cost of capital" or "the low collateral price - the high cost of capital" equilibrium is attained. Kiyotaki and Moore(1995) built a model based on the incomplete contract approach, and derived procyclical deterministic dynamics of land prices. $^{22}$ When Kiyotaki and Moore's model is put into our empirical perspective, the story is the following. First, a productivity shock pushes up output so that the demand for land will increase too. Land prices go up, and this triggers a further increase in land prices. This land price dynamics is predictable in the sense that it is deterministic, but does not necessarily mean an arbitrage opportunity. As land prices go up, the debts and investments of firms also increase because firms are able to borrow more as the collateral value of real estates 
goes up. This further boosts up activities in the economy. On the other hand, stock prices respond to the shock in GNP contemporaneously, so that stock prices seemingly lead land prices. Since the stock price of the firm embodies the value of the real cstates which held by the firm, stock prices also go up with land prices. But this mechanism will not last forever. When land prices become too high, the price effect chokes demand for land so that finally land prices will begin to go down. Then the "multiplier process" works in the opposite downward direction. Land prices go down, firms' debts and investments decline, and the whole economy slows down.

Kiyotaki and Moore presented a sophisticated dynamic general equilibrium model, however their model also has some drawbacks. In our context, the most important shortcoming is that there is no room for monetary shocks in their model. For example, Kiyotaki and Moore implies that the value of collateral leads the debt of the representative firm. In other words, land price Granger-causes the amount of bank loans. This is because the value of collateral determines the amount of loans in their model (Figure 5.1). This is a very strong implication, and it is hard to believe that it does hold in practice.

Another important aspect of the market imperfection in the real estate market is recently modeled by Jeremy Stein(1995). It is observed that, in the housing market, trading volume is high when prices are going up, and it is low when prices are going down. He explained this fact by the effect of large downpayments have to be paid in the housing market transactions. This theory also predicts that once large positive shock hit the market, it will cause the multiplier process. Because the people who sold their real estates got enough money to pay downpayments on their hands, the demand for the real estates will further increase. It is commonly said that from 1985 to 1988 , the land price appreciation first began at the real estates for commercial use in Tokyo metropolitan area, and then the boom spread out to other big cities and the real estates for residential use. This is formally studied and established as the stylized fact by Nishimura(1990). This fact perfectly fits to the transactions cost view: initial shock increased the price of the real estates for commercial use in Tokyo. It raised collateral value of land owners, and lead the increase of land prices in other areas and for other uses.

There are only few empirical studies about this issue. Yoshino (1992) studied the Japanese "non-bank" financial institutions, whose presence in the Japanese financial system 
became prominent in the late $1980 \mathrm{~s} .{ }^{23}$ Those firms heavily rely on the borrowing from large financial institutions. In the period of the "bubble economy," non-banks played important roles as the lenders to the real estate firms. The large banks used non-banks as indirect way to lend to the risky borrowers. (Many non-banks belong to financial Keiretsu, the corporate groups in Japan.) In the appendix of his paper, Yoshino found the large banks' lending to non-banks and real estate companies is significant in explaining land price changes. Hamao and Hoshi (1991) also suggested that the "stock Granger-causes land" result in their bivariate VAR can be explained by the collateral hypothesis.

In the remainder of this section, some predictions of the loan constraint story are examined using the bank loan data, as Yoshino (1992) did. Yoshino's paper used the data after 1978, while we use data starting in 1968. In order to lengthen the time series, we limit the bank loans only to real estate companies. Also Yoshino's data is new loans for equipment funds, but our data is outstanding loans and discounts for both equipment and operating funds.

Figure 5.2 shows the growth rates of the land price and bank loans to the real estate sector. From this graph, it is clearly seen that bank loan leads land price. Table 5.1 summarizes the regression results for the determinants of the real land price inflation rate (GLAND). The increase of the interest rate (ARATE) is insignificant once lagged variables are included. This is not supportive evidence for a neoclassical model. (Using the real interest rate level instead of ARATE do not change any results in Tables 5.1 and 5.2, but the real interest is less significant in all regressions.) On the other hand, the growth rate of loans to real estate companies (GLOAN) is an important factor in explaining GLAND. Current GLOAN becomes insignificant when its lagged variables are included, but lagged GLOAN is even more significant. Own lagged variables of GLAND are also important in determining current GLAND.

In Table 5.2, we looked at the determinants of GLOAN. GLAND is significant in explaining GLOAN if only current variables were used as the right-hand side variables. Once lagged variables are introduced GLAND becomes insignificant. ARATE is also insignificant if the lagged variables are included. Its own lagged variables and current growth rate of money (GMONEY) are the most important factors in explaining GLOAN. But, since the lagged 
GMONEY is insignificant, it is not clear that if GMONEY causes GLOAN, or the other way around, or both of them are responding some other factor(s).

Overall, the messages from Tables 5.1, 5.2, and Figure 5.2 are very clear. In the determination of land prices, quantity variables (GLOAN, GMONEY) play much more important roles than the interest rate. Our results do support the lending constraint view, but do not support Kiyotaki and Moore's naive prediction about the Granger causality between land price and the debt. There is evidence that current and past bank loans amount determines the land price, however the land price increase does not cause the increase of bank loans. Also in bivariate VAR shown in Table 5.3, Kiyotaki and Moore's prediction is directly tested. Again, there is the strong evidence that the loans Granger-cause the land price, but the land price does not cause bank loans.

In sum, results in this section are consistent with the following view. An initial shock seems to be a sudden increase in bank loans. This may have been caused by monetary policy which allowed credit (restraint) expansion rather than lowering official/interbank interest rates or by financial liberalization which allowed banks to enhance diversifying (or aggressive risk taking, in retrospect) and expanding their loan portfolio. Then the initial shock of increased loans prompted an increase in demand for fixed investment and land, which in turn increased stock prices and land prices. Once stock and land prices started to increase, the multiplier process implied by theory (the Kiyotaki-Moore model and the transactions cost model) worked. Increases in stock prices made it possible to raise funds more by direct financing and invest more, which increased demand for land. Increases in land prices increased collateral values, so that firms could borrow more and invest more. Once this process continues for some periods, one might expect that the markets attract some speculative activities. Those who make financial bets on further increases in stock and land prices are rewarded with capital gains, so they further increase the size of their bets and attract new comers to the betting game. However, it is difficult to differentiate price increases due to fundamentals (say, productivity increases) from those due to bubbles (say, speculation) in empirical results of this section. The Kiyotaki-Moore model, as well as the neoclassical model of the previous section, preclude the 
existence of rational and irrational bubble.

\section{Concluding Remarks}

In this paper, the behavior of Japanese stock and land prices have been discussed, with a particular focus on the boom and bust in last ten years. A complex chain of events is needed to explain the asset behaviors. Our empirical results suggest (i) that data are consistent with a hypothesis that the initial seed of bubbles are sown by a sharp increase in bank lending to real estates; (ii) that a considerable comovement between stock and land prices is consistent with a theory that emphasize the relationship between the collateral value of land for cash flow constrained firms; (iii) that asset price increases from the mid-1987 to the mid-1989 is consistent with the movement of fundamentals; (iv) the stock price increase in the second half of the 1989 and the land price increase in 1990 is not explained by any model of fundamentals or rational bubbles.

Although our findings in this paper are suggestive of the existence of the stochastic bubbles, no clear-cut, positive evidence was discovered. Empirical results give us a clue that bank lending may be important in the determination of land prices in Japan. This might be due to the lending constraint like one in Kiyotaki and Moore and one in Stein's transactions (downpayment) costs model. The bank lending may explain the initial shock to the asset price in 1986.

Caveats have to be noted in our conclusions stated above. There are obvious difficulties in establishing evidence for "bubbles" in the stock and land prices. First, as briefly noted in section 4 , tests of bubbles and fads in asset prices require calculating fundamental prices. However, calculating fundamentals involve many simplifying assumptions, in particular assumptions on expectations on future variables. So in the second half of the section 3 , we tried to look at whether the pattern of asset price behaviors were consistent with other economic variables, without discussing so much about the level of the asset prices and which caused which. Our conclusion is that, after the middle of the 1987, the movement of asset prices are consistent with fundamentals changes. This is consistent with the results in section 2 , in that Japanese stock and land prices are explained by each other and became more predictable in this period. What is unresolved is an initial increase of the asset prices in 1986. One strong suspect 
for the initial shock is the increase in bank lending, which was emphasized in section 4 and 5 .

Second, the asset price boom from the mid 1980s to early 1990s is just a one time event. Some people might think that the boom was not a bubble at all, but even such people would agree that the boom will not occur again for some time in the same magnitude as observed in the last ten years. As it is often criticized in the empirical studies on the long run swing in stock prices (Poterba and Summers, 1986, for example), it is very hard to give a fully persuasive empirical argument for such low frequency events. Sophisticated econometric techniques which depend on asymptotics can be in vain because of the small sample bias.

A number of issues are left for future research. First, we discussed on the effect of monetary policy on asset prices, but we did not cover the conduct of monetary policy itself. When it is discussed, the effects of international policy coordination and the target zone of the yen/dollar exchange rate on monetary policy should be examined. Also, the structural change of money demand function around 1985 due to the rapid financial deregulation would be important in this regard.

The role of demographic dynamics is another important issue for the determination of the land prices. The Japanese economy will face sharp decline of younger populations in next fifty years. In the neoclassical world, land prices should be determined by population and the supply of land. So far, our analysis in section 4 and related research like Ito (1993) and Sachs and Boone(1988) assumed constant population growth rate in their models. We need to research on the effect of demographic factor on the Japanese housing demand like Mankiw and Weil (1989) for the U.S. economy.

With all these caveats, this study at least shed some lights on the linkage between the stock and land price inflation processes, which did not attract a proper level of attention. The linkage is important in understanding how the initial shock would be propagated through financial markets. Our work suggests the dynamic interaction lends itself to a view that the land and stock prices are connected, and that gives some clue to the asset price inflation process. Once the shock is given, there is a multiplier process between stock and land prices. 
NOTES:

1. The Nikkei 225 index was 11,542 in December 1984 , but increased to 38,915 yen in December 1989. Then the index plummeted to 15,951 in June 1992. The commercial land price for large cities increased from 38.4 in 1986 to 103.0 in 1991 . The index decreased to 71.4 in March 1993.

2. The index includes cities (urban area) in Japan, and covers different kinds of usage: residential, industrial and commercial. The Institute also publishes the disaggregated indices, "average, six-metropolitan city" index, as well as "residential," "industrial," and "commercial" for each of "nation-wide" and "six-metropolitan." Although all indices behaves similarly in the long run, suggesting that the major driving force in land price is nation-wide aggregate shock, the magnitudes of changes and the timings of sharp upturn or downtum are slightly different for different indices. For details of these movements, see Ito (1992; pp. 416-418). For the purpose of macroeconomic investigation, we mainly deal with the nation-wide, aggregate index in this paper.

3. There are other indices frequently used in analysis of land price movements. The National Land Agency surveys and publishes the unit land price of more than 17,000 points in Japan on January 1 every year, in its calculation of the Official Land Price Index (Koji Chika). This is most comprehensive land price survey in Japan. However, this land index is available only since the beginning of the 1970s. The prefectural government also surveys and publishes the land index as of July 1, every year. The index is available only for the last decade or so. Hence, the Japan Real Estate Institute index has the longest time series.

4. All land price indices described in note 3, including the land price index of the Japan Real Estate Institute, share a defect in not reflecting the market conditions promptly, because the land prices of particular points are "assessed" by the assessor. Although assessment reflect transaction prices in comparable places near the assessment point, it may not reflect quickly changing prices if transactions are not frequent. The Official Land Price, for particular points, has been also known to be undervaluing the market price by 20 to 30 percent. (If it is 
consistently undervalue all the time, this does not cause the problem for our purpose.) Since prices for individual survey points are not published for the Japan Real Estate Institute index, it is difficult to make inference on its deviation from the market price.

5. Major results in this section are already appeared in Ito and Iwaisako(1992) and Iwaisako(1993).

6. It is believed to be the case that stocks of firms with large inventory of land increased more than otherwise in the early part of the bubble of late 1980 s in Japan. It was ironic that some declining industries got investors' attention this way. A steel company with obsolete steel mills at the Tokyo Bay and a beer brewery with excess capacity in Tokyo. The Sapporo Beer in fact developed the old brewery at Ebisu, Tokyo into a housing complex to take advantage of increased market rents.

7. Ito (1992, JJIE) tried to exploit this relationship in its investigation of land price determination in Japan.

8. Our $\mathrm{r}$ is certificate deposit new issue rate (90-179 days). For $\mathrm{g}$, the three month moving average of the one year growth rate of the sales of large-scale retail stores is used. We used consumption data for $g$ rather than output data such as GDP or industrial output. That is because the consumption movement is supposed to reflect the expectation of the future permanent income, so that it better approximates the expectation of the future output or earnings than the actual output or earnings.

9. From the Gordon valuation formula,

$$
R_{t+1}=\frac{P_{t+1}}{P_{t}}-1=\frac{D_{t+1} /(r-g)}{D_{t} /(r-g)}-1
$$

and $D_{t+1}=(1+g) D_{t}$. So $R_{t+1}$ is equal to " $g$ ", if the $r$ is fixed.

10. This calculation holds approximately, either if we assume that all the change in " $r$ " happened at the beginning, or if we assume that there were small changes spreading over the period. 
11. This type of model has its origin in the multiple solution problem of linear rational expectations models (see, ch.5 of Blanchard and Fischer, 1989). Thus it is called "rational" bubbles. However, this model is not consistent with the assumption of fully rational agents or common knowledge, since it is violating (3.4). The full rationality assumption can be very restrictive. See chapter 7 of Campbell, Lo, and MacKinlay, for other various economic arguments that the "rational" bubble model is unlikely to be a good description of speculative behaviors in asset markets.

12. Rational investors will not invest to negative bubbles. So we should add the condition that $b_{t} \geq 0$ for all $t$.

13. For example, Fama and French(1989), Lo and MacKinlay(1988), Poterba and Summers(1988).

14. More precisely, rational bubbles might be the reason of the low power of Shiller type volatility test in small sample. We thank Prof.Flood for this comment.

15. See Campbell (forthcoming) for the survey of the term structure literature and the interesting application to the recent U.S. monetary policy experience.

16. The short-term rate is certificate deposit new issue rate (90-179 days). The long-term rate is the yield of government bonds listed on Tokyo Stock Exchange (10 year benchmark). Roughly speaking, Figure 3.3 corresponds to Campbell and Hamao (1993; figure 4.7), although their sample period is 1980:11-1990:8, ours is 1984:1-1993:12, and the short term rates are different.

17. According to the Modigliani-Miller theorem (in the world with perfect information and no corporate tax, among other things), there is no reason to believe that the dividend-price ratio is useful to predict asset returns. The dividend-price ratio turned out to be useful in predicting stock prices in the United States, probably because it signals to investors some information revealed to the firm's management. In the United States, the dividend-price ratio has been relatively stable, and the mean stays constant in the long run. If the signaling story of firms' dividend policy is true, dividends represent "fundamentals" in the future. So, there is a stable (stationary) relationship between the equity price and the signal of its 
"fundamentals," even though both of them are non-stationary time series. See also note 17. 18. See also Campbell-Lo-MacKinlay(1993), chap.7. The formulation in this paper is following Campbell and Ammer(1993).

19. By the linear approximation procedure, (1) can be rewritten as the following.

$$
\begin{aligned}
& e_{t+1}-E_{t} e_{t+1}=\left(E_{t+1}-E_{t}\right)\left\{\sum_{j=0}^{\infty} \rho^{j} \Delta d_{t+1+j}-\sum_{j=0}^{\infty} \rho^{j} r_{t+1+j}-\sum_{j=0}^{\infty}\right. \\
& \left.\rho j e_{t+1+j}\right\} \\
& \text { where } \\
& \text { e }=\text { excess return } \\
& \Delta d=\text { Growth of dividend (first difference of } \mathrm{log} \text { dividend) } \\
& r=\text { real interest rate } \\
& \rho=\text { the discount rate implied by the log-linear approximation procedure } \\
& \text { If constant dividend-price ratio (D/P) is assumed, } \\
& \rho=(1+D / P)^{-1}
\end{aligned}
$$

See Campbell and Ammer(1993) for details

20. We thank Professor Campbell for his comments which have helped the following discussion.

21. However, if we compare the rent/price ratios of large world cities (for example, Noguchi, 1989, ch.3), Tokyo's rent/price ratio is much lower than other cities like New York and London.

22. However, they made some stringent assumptions. In their model, the liquidity constrained firms borrow as much as they can so that either all firms are always liquidity constrained or they are not maximizing their profits. There is no Tobin's $Q$ in their model. Also they assume perfect foresight.

23. Typical "non-banks" include consumer loan, (small) credit card, leasing, and housing loan specialized companies. 


\section{References}

Asako, Kazumi (1992) "Mechanism of asset prices (in Japanese: Shisan kakaku no mechanism)," in Ito and Noguchi eds. Nihon keizaino stock ka, Nihon keizai shinbunsya.

, Kanou Satoru, and Sano Naofumi (1990) "Stock Price and Bubbles (in Japanese: Kabuka to Bubble), in Japanese stock and land prices (Nihon no kabuka chika), eds. K.G.Nishimura and Y.Miwa eds., The University of Tokyo Press.

-------, Kuninori, Inoue, and Murase (1989) "The evaluation of real estates and the measurement of Tobin's Q and Multiple Q (in Japanese: Tochi hyouka to Tobin no Q / Multiple Q no keisoku)," Keizai Keiei Kenkyu, the Japan Development Bank, vol.10-3.

Blanchard, Olivier(1979) "Speculative bubbles, crashes, and rational expectations," Economics Letters, 3.

------, and Mark W. Watson (1982) "Bubbles, rational expectations, and financial markets," in P.Wachtel ed., Crisis in the Economic and Financial Structure, Lexington Books.

Campbell, John Y. (1991) "A variance decomposition for stock returns," Economic Journal 101, $157-179$.

-------, forthcoming, "Some Lessons from the Yield Curve, " Journal of Economic Perspectives. ------, and John Ammer (1993) "What moves the stocks and bond markets?: A variance decomposition for long-term asset returns, " Journal of Finance, Vol.XLVIII, No.1, 3-37.

---.--, and Hamao Yasushi (1993) "The interest rate process and the term structure of interest rates in Japan," in Kenneth Singleton ed., Japanese Monetary Policy, University of Chicago Press.

------, Andrew W. Lo, and A. Craig MacKinlay (1994) The Econometrics of Financial Markets, unpublished manuscripts, Harvard and MIT.

Fama, Eugene F. and Kenneth R. French (1989) "Business Conditions and Expected Returns on Stock and Bonds," Journal of Financial Economics 25, 23-49.

Fazzari, Steven M., R.Glenn Hubbard, and Bruce C. Petersen (1988) "Financing constraints and corporate investment", Brookings Papers on Economic Activity, 1988:1, 141-195.

Ferson, Wayne, and Campbell R. Harvey (1994) "An Exploratory Investigation of the Fundamental Determinants of National Equity Market Returns," in J.A.Frankel ed. The Internationalization of Equity Markets, The University of Chicago Press. 
Flood, Robert P. and Robert J. Hodrick, "On Testing for Speculative Bubbles," Journal of Economic Perspectives, vol. 4, no. 2, Spring 1990: 85-101.

French, Kenneth and James Poterba (1991) "Were Japanese stock prices too high?" Journal of Financial Economics, vol.29, pp.23-50.

Froot, Kenneth A. (1989) "New Hope for the Expectations Hypothesis of the Term Structure of Interest Rates, " Journal of Finance, Vol.44, 283-305.

------, and Maurice Obstfeld (1991) "Intrinsic Bubbles: The Case of Stock Prices," American Economic Review, Vol.81, No.5, 1189-1214.

Hamao, Yasushi, and Takeo Hoshi (1991) "Stock and land prices in Japan", unpublished working paper, Columbia University and U.C. San Diego.

Hoshi, Takeo, Anil Kashyap, and David Scharfstein (1991) "Corporate Structure, Liquidity, and Investment: Evidence from Japanese Industrial Groups," Quarterly Journal of Economics, 106: 33-60.

Ito, Takatoshi (1992) The Japanese Economy, MIT Press.

, (1993) "The land/housing problem in Japan: A macroeconomic approach", Journal of the Japanese and International Economies, January.

-.--- and Hirono Nosse Keiko (1993) "Efficiency of the Tokyo Housing Market," Bank of Japan Monetary and Economic Studies, vol.11, 1-32.

...-- and Tokuo Iwaisako (1992) "Time Series Analysis of Japanese Stock and Land Prices," mimeo. Bank of Japan

Iwaisako, Tokuo (1993) "Econometric Tests of Japanese Stock and Land Prices," mimeo. Harvard University.

Japan Security Analysis Institute (1988) The Research Report on Japanese Stock Price Level (in Japanese, Nihon-no Kabukasuijyun Kenkyu Group Hokokusyo).

Kashyap, Anil, Jeremy C. Stein, and David W. Wilcox (1993) "Monetary policy and credit conditions: Evidence from the composition of external finance," American Economic Review, 83, no.1.

Kiyotaki, Nobuhiro, and John Moore (1995) "Credit cycles," NBER Working Paper \#5083. LeRoy, Stephen F. and Richard Porter (1981) "The Present Value Relation: Tests Based on Variance Bounds," Econometrica, 49, 555-577. 
Lo, Andrew W. and A.Craig MacKinlay (1988) "Stock market prices do not follow random walks: Evidence from a simple specification Test," Review of Financial Studies, vol.1, no. 1 .

Mankiw, N.Gregory and Daivid N. Weil (1989) "The baby boom, the baby bust, and the housing market", Regional Science and Urban Economics, 19, no.2.

Marsh, Terry A. and Robert C. Merton (1986) "Dividend Variability and Variance Bounds Tests for the Rationality of Stock Market Prices", American Economic Review, 76, 483497.

Nishimura, Kiyohiko G. (1990) The mechanism of land price determination in Japan (in Japanese: Nihon no chika kettei mechanism), in Japanese stock and land prices (Nihon no kahuka chika), Nishimura and Y.Miwa eds., The University of Tokyo Press.

Noguchi, Yukio (1989) Economics of Land (in Japanese: Tochi no keizaigaku), Nihonkeizai shinbunsya.

Phillips, Peter C.B. and Ouliaris (1990) "Asymptotic Properties of Residual Based Tests for Cointegration", Econometrica, 58, 165-93.

Poterba, James M. and Lawrence H. Summers (1986) "Mean reversion in stock prices: Evidence and implications," Journal of Financial Economics, 22, 27-59.

Sachs, Jeffrey and Peter Boone (1988) "Japanese structural adjustment and the balance of payments," Journal of the Japanese and International Economies, vol.2, no.3.

Scharfstein, David S. (1994) "Corporate finance and macro". lecture note, MIT.

Shiller, Robert J. (1981) "Do Stock Prices Move Too Much to Be Justified by Subsequent Changes in Dividends?" American Economic Review, 71, 421-436.

Stein, Jeremy S. (1995) "Prices and Trading Volume in the Housing Market: a Model with Down-payment Effect," Quarterly Journal of Economics, CX: 379-406.

Stiglitz, Joseph E. and Andrew Weiss (1981) "Credit rationing in markets with imperfect information," American Economic Review, vol.71 393-410.

Summers, Lawrence H. (1991) "The Scientific Illusion in Empirical Macroeconomics," Scandinavian Journal of Economics, 93 (2), 129-148.

Ueda, Kazuo (1990) "Are Japanese stock prices too high?" Journal of the Japanese and International Economies, vol.14, December. 
(1992) Monetary Policy under the Balance of Payments imbalance (in Japanese: Kokusai syushi fukinkouka no kinyu seisaku). Toyo keizai shinpo sya.

West. Kenneti D., (1987) "A Specification Test for Speculative Bubbles," Quarterly Journal of Economics, 102 : 553-80.

Yoshino, Naoyuki (1992) "The roles of non-bank financial institutions and monetary policy (in Japanese: Non-banku no kinou to kinyuuseisaku)," in The Analysis of Modern Japanese Financial System (Gendai nihon no kinyu bunseki), eds. Y. Yoshino and A.Horiuchi, The University of Tokyo Press. 


\section{Table 2.1 : Basic Statistics of Stock and Land Prices}

STOCK: The index of the first section of Tokyo Stock Exchange. LAND: The country-wide average of the average of all uses. ESTOCK/ELAND: Excess Returns of Assets over Call Rate (Annualized).

Semi-Annual Data From 1956:01 To 1993:01 Observations 75

\section{A. Statistics on Series ESTOCK}

$\begin{array}{lr}\text { Sample Mean } & 7.81938 \\ \text { Standard Error } & 27.74628 \\ \text { Skewness } & -0.39932\end{array}$

B. Statistics on Series ELAND

$\begin{array}{lr}\text { Variance } & 769.85579 \\ \text { SE of Sample Mean } & 3.20386 \\ \text { Kurtosis } & 0.17648\end{array}$

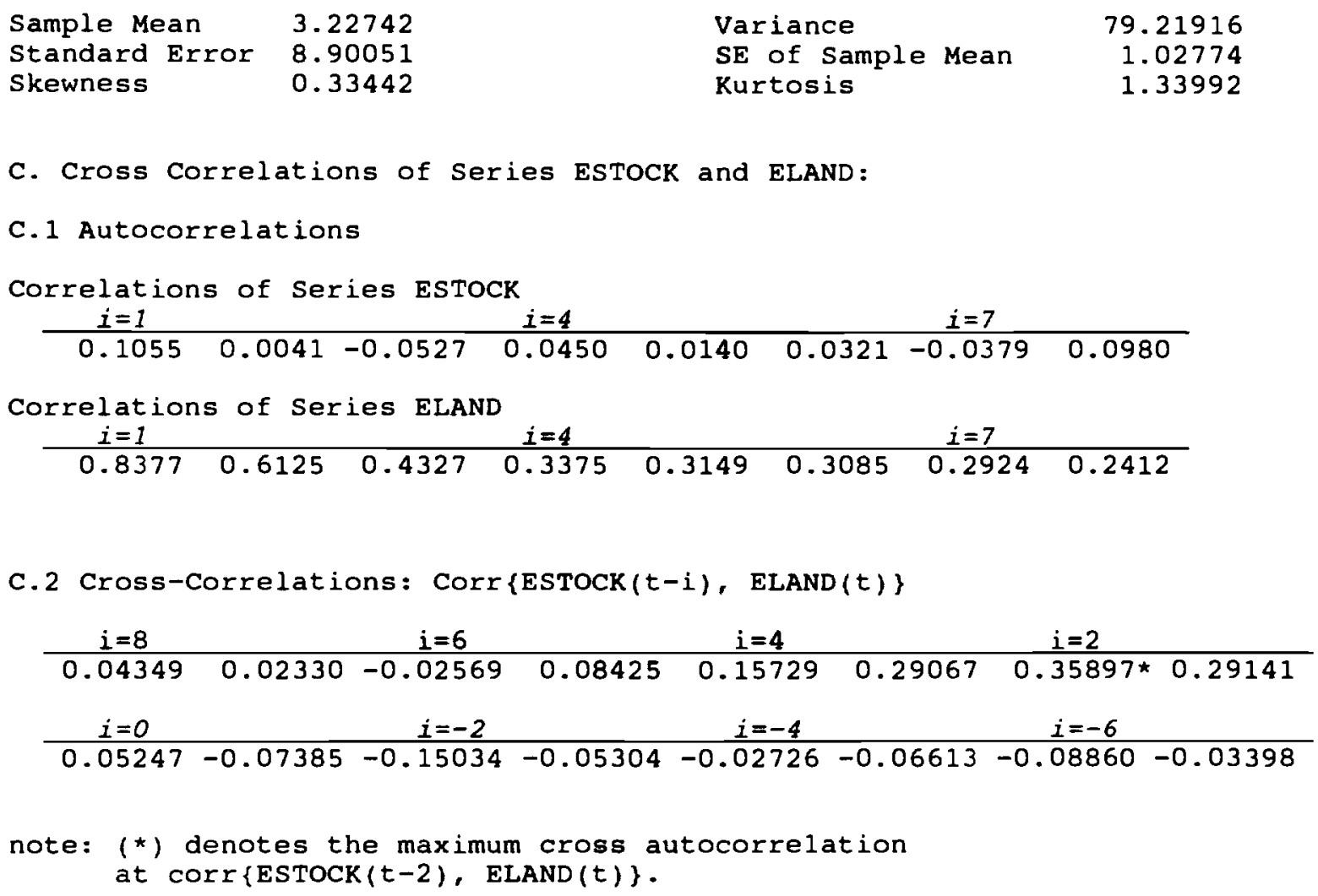




\section{Table 2.2 : Dickey-Fuller Tests for Real Asset Prices}

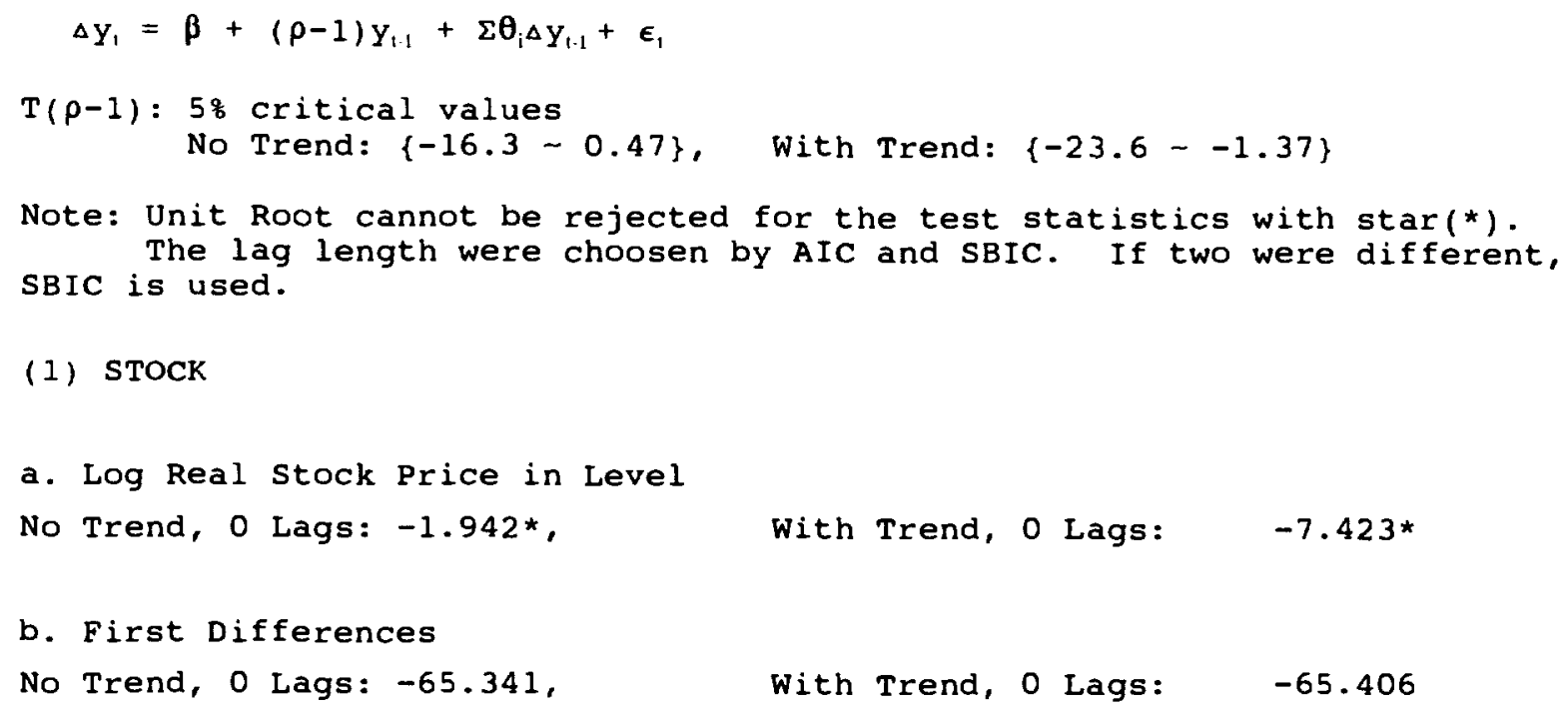

2) LAND

a. Log Real Land Price in Level

No Trend, 5 lags: $-4.879 *$ With Trend, 4 lags: -7.351 *

b. 1 First Differences

No Trend, 4 Lags: $-13.650 *, \quad$ With Trend, 4 Lags: -21.490*

b.2 The First Difference: After 1960:1

No Trend, 4 Lags: $-22.384, \quad$ With Trend, 4 Lags: -29.544

C. Excess Return

No Trend, 1 Lags: -26.713, With Trend, 1 Lags: -41.118 


\section{Table 2.3 : Variance Ratio Tests}

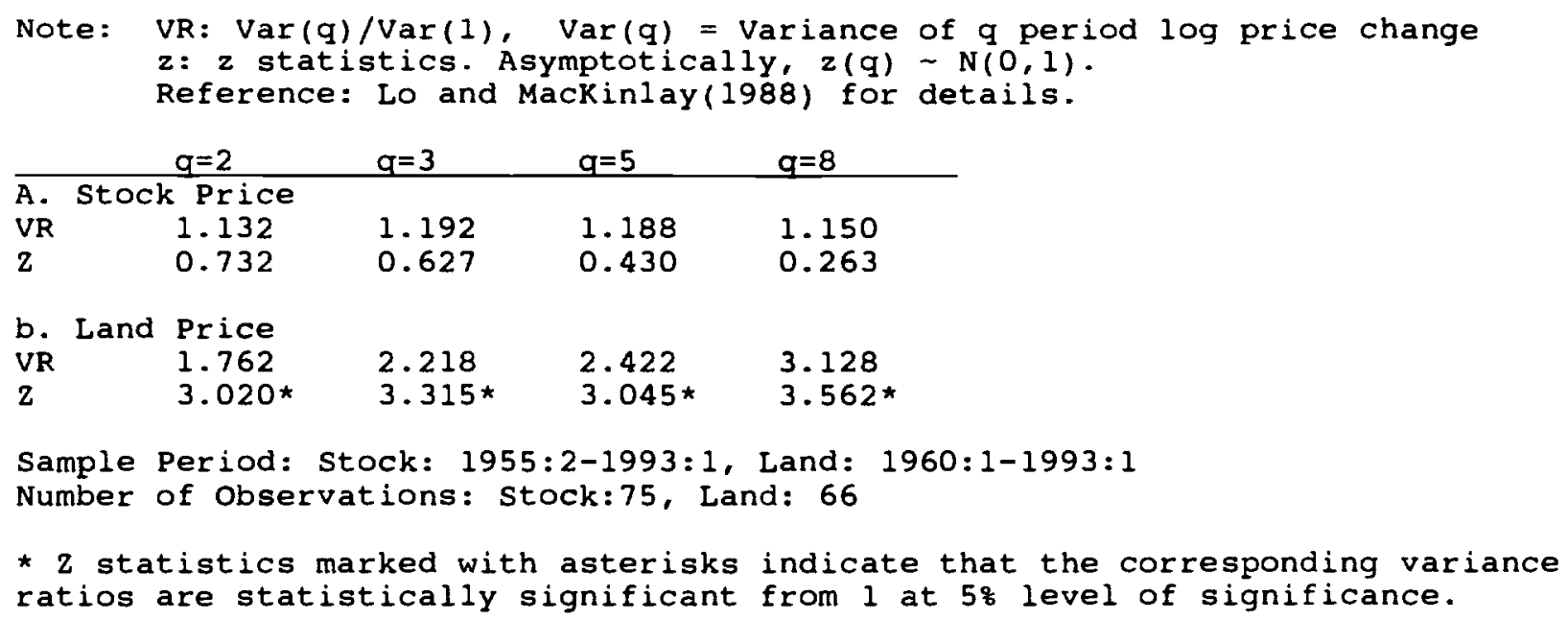




\section{Table 2.4 Bivarate VAR(3): estock and eland}

(1) Full Sample; 1960:1-1993:1

\begin{tabular}{|c|c|c|c|c|c|}
\hline $\begin{array}{l}\text { Dependent } \\
\text { R Bar } \star \star 2 \text { : }\end{array}$ & $\begin{array}{cc}\text { Variable ESTOCK } & - \\
0.0050, & \text { D.W.: } 2 . \\
11 \mathrm{aq} & 2 \mathrm{laq}\end{array}$ & $\begin{array}{l}\text { Estimatio } \\
0012 \\
\quad 31 \mathrm{aq} \\
\end{array}$ & $\begin{array}{l}n \text { by Least } \\
\text { constant }\end{array}$ & $\begin{array}{l}\text { Squares } \\
\text { F-sta }\end{array}$ & atistic \\
\hline ESTOCK & $\begin{array}{cc}0.0965 & -0.0220 \\
(0.7475) & (-0.1548)\end{array}$ & $\begin{array}{c}0.0967 \\
(0.6547)\end{array}$ & $\begin{array}{c}1.9499 \\
(0.1594)\end{array}$ & ESTOCK : & $\begin{array}{l}0.3260 \\
(0.8065)\end{array}$ \\
\hline ELAND & $\begin{array}{cc}0.9681 & -2.2435 \\
(1.1616) & (-2.0230)\end{array}$ & $\begin{array}{c}0.8512 \\
(1.0815)\end{array}$ & & ELAND: & $\begin{array}{c}1.7704 \\
(0.1625)\end{array}$ \\
\hline $\begin{array}{l}\text { Dependent } \\
\text { R Bar } \star \star 2 \text { : }\end{array}$ & $\begin{array}{l}\text { Variable ELAND - E } \\
0.7633, \text { D.W.: } 2 .\end{array}$ & $\begin{array}{l}\text { stimation } \\
0131\end{array}$ & by Least & Squares & \\
\hline ESTOCK & $\begin{array}{c}0.0252 \\
(1.1501)\end{array}$ & $\begin{array}{c}0.0204 \\
(0.8946)\end{array}$ & $\begin{array}{l}-0.1153 \\
(-0.3981)\end{array}$ & ESTOCK: & $\begin{array}{l}6.7285 \\
(0.0005)\end{array}$ \\
\hline ELAND & $\begin{array}{cc}0.9518 & -0.4042 \\
(7.4149) & (-2.3665)\end{array}$ & $\begin{array}{c}0.1855 \\
(1.5301)\end{array}$ & & ELAND: & $\begin{array}{l}36.3326 \\
(0.0000)\end{array}$ \\
\hline
\end{tabular}

(2) After the First Oil Schock; 1974:1-1993:1

Dependent Variable ESTOCK - Estimation by Least squares

R Bar **2: -0.0141 , D.W.: 2.1440

\begin{tabular}{llllll} 
& $1 \mathrm{lag}$ & $2 \mathrm{lag}$ & $3 \mathrm{laq}$ & constant & F-Statistic \\
\hline ESTOCK & 0.1005 & -0.0590 & 0.1336 & 0.4463 & ESTOCK: 0.2738 \\
& $(0.5798)(-0.3182)$ & $(0.6696)$ & $(0.1849)$ & & $(0.8438)$ \\
ELAND & $0.6891-1.6719$ & 0.0212 & & ELAND: 1.4518 \\
& $(0.5609)(-1.1837)$ & $(0.0209)$ & & $(0.2462)$
\end{tabular}

Dependent Variable ELAND - Estimation by Least squares R Bar $\star \star 2: 0.6028$, D.W.: 1.8728

\begin{tabular}{lllllr} 
& $1 \mathrm{laq}$ & $2 \mathrm{laq}$ & $31 \mathrm{aq}$ & constant & F-Statistic \\
\hline ESTOCK & 0.0612 & 0.02788 & 0.0221 & -0.7837 & ESTOCK: 2.8873 \\
& $(2.4926)$ & $(1.0621)$ & $(0.7827)(-2.2921)$ & & $(0.0507)$ \\
LAND & 0.7037 & -0.1998 & -0.0936 & & \\
& $(4.0430)$ & $(-0.9987)$ & $(-0.6505)$ & ELAND: 7.8529 \\
& & &
\end{tabular}

(3) Befrore Plaza Accord; 1960:1-1985:1

Dependent Variable ESTOCK - Estimation by Least Squares R Bar **2: 0.03367 , D.W.: 1.9400

\begin{tabular}{|c|c|c|c|c|c|c|}
\hline & $11 \mathrm{ag}$ & $2 \mathrm{lag}$ & $31 \mathrm{ag}$ & constant & F-sta & tistic \\
\hline ESTOCK & $\begin{array}{c}0.0165 \\
(0.1092)\end{array}$ & $\begin{array}{c}0.0591 \\
(0.3512)\end{array}$ & $\begin{array}{l}-0.0017 \\
(-0.0099)\end{array}$ & $\begin{array}{c}2.5843 \\
(1.2988)\end{array}$ & ESTOCK : & $\begin{array}{c}0.0434 \\
(0.9878)\end{array}$ \\
\hline ELAND & $\begin{array}{c}1.1130 \\
(1.3302)\end{array}$ & $\begin{array}{l}-2.5206 \\
(-2.2793)\end{array}$ & $\begin{array}{c}1.1228 \\
(1.4573)\end{array}$ & & ELAND : & $\begin{array}{c}1.8855 \\
(0.1460)\end{array}$ \\
\hline
\end{tabular}

Dependent Variable ELAND - Estimation by Least squares R Bar $\star \star 2: 0.7684$, D.W.: 2.0107

\begin{tabular}{|c|c|c|c|c|c|c|}
\hline & $11 \mathrm{ag}$ & $21 \mathrm{ag}$ & $3 \mathrm{laq}$ & constant & \multicolumn{2}{|c|}{ F-statistic } \\
\hline ESTOCK & $\begin{array}{c}0.1133 \\
(4.1306)\end{array}$ & $\begin{array}{c}0.0253 \\
(0.8313)\end{array}$ & $\begin{array}{c}0.0170 \\
(0.5424)\end{array}$ & $\begin{array}{l}-0.1300 \\
(-0.3601)\end{array}$ & ESTOCK : & $\begin{array}{c}5.7704 \\
(0.0020)\end{array}$ \\
\hline LAND & $\begin{array}{c}0.9471 \\
(6.2465)\end{array}$ & $\begin{array}{l}-0.4349 \\
(-2.1701)\end{array}$ & $\begin{array}{c}0.2237 \\
(1.6024)\end{array}$ & & ELAND: & $\begin{array}{l}25.9947 \\
(0.0000)\end{array}$ \\
\hline
\end{tabular}

Note: (i) Coefficients -- t-statistics in parentheses (ii) F-statistic - Significance level in parenthese 


\section{Table 3.1 Permanent Change in " $r$ "}

\begin{tabular}{llll}
$\mathbf{r}$ & $\mathbf{g}$ & $\mathrm{D} / \mathrm{P}$ & $1 /(\mathrm{r}-\mathrm{g})$ \\
\hline $4(\%)$ & $3(\%)$ & $3(\%)$ & 100 \\
5 & 3 & 3 & 50 \\
6 & 3 & 3 & 33.3
\end{tabular}

Table 3.2 Temporally Change in " $r$ "

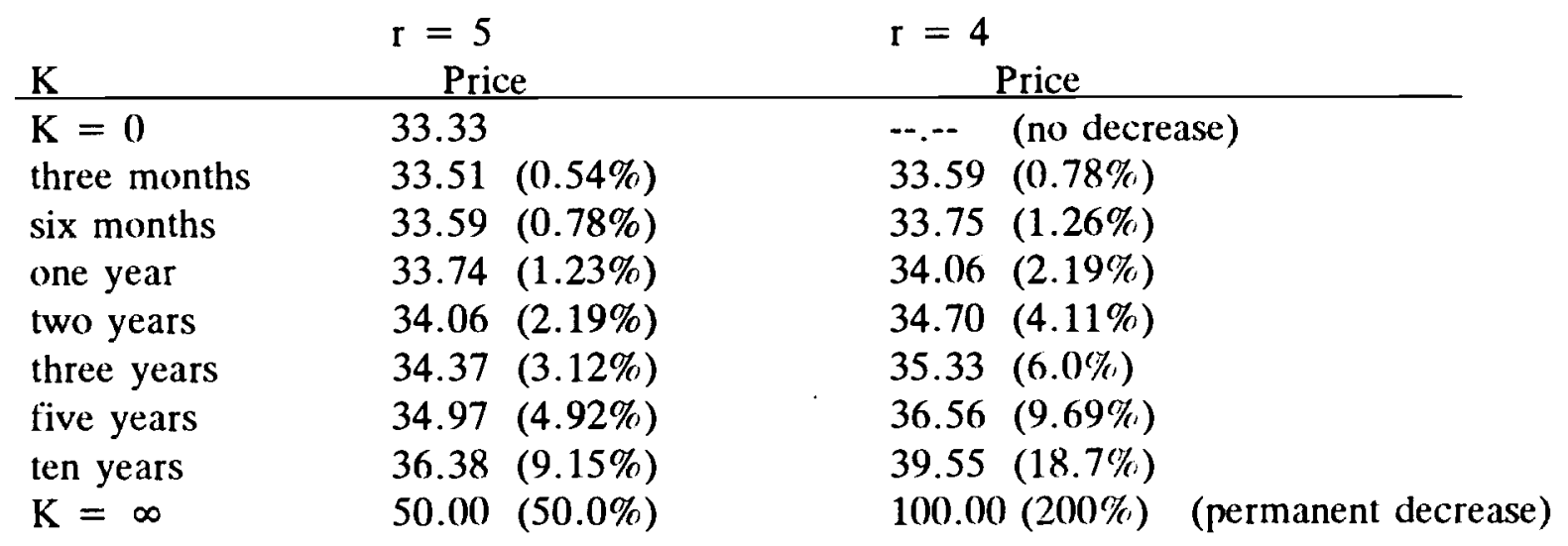




\section{Table 4.1 Coefficients of VAR System Including Macro-variables}

VAR(1): ESTOCK, ELAND, RRATE, GLOAN, ARATE, LEPR (1) Semi-Annual Data From 1969:2 To 1993:1

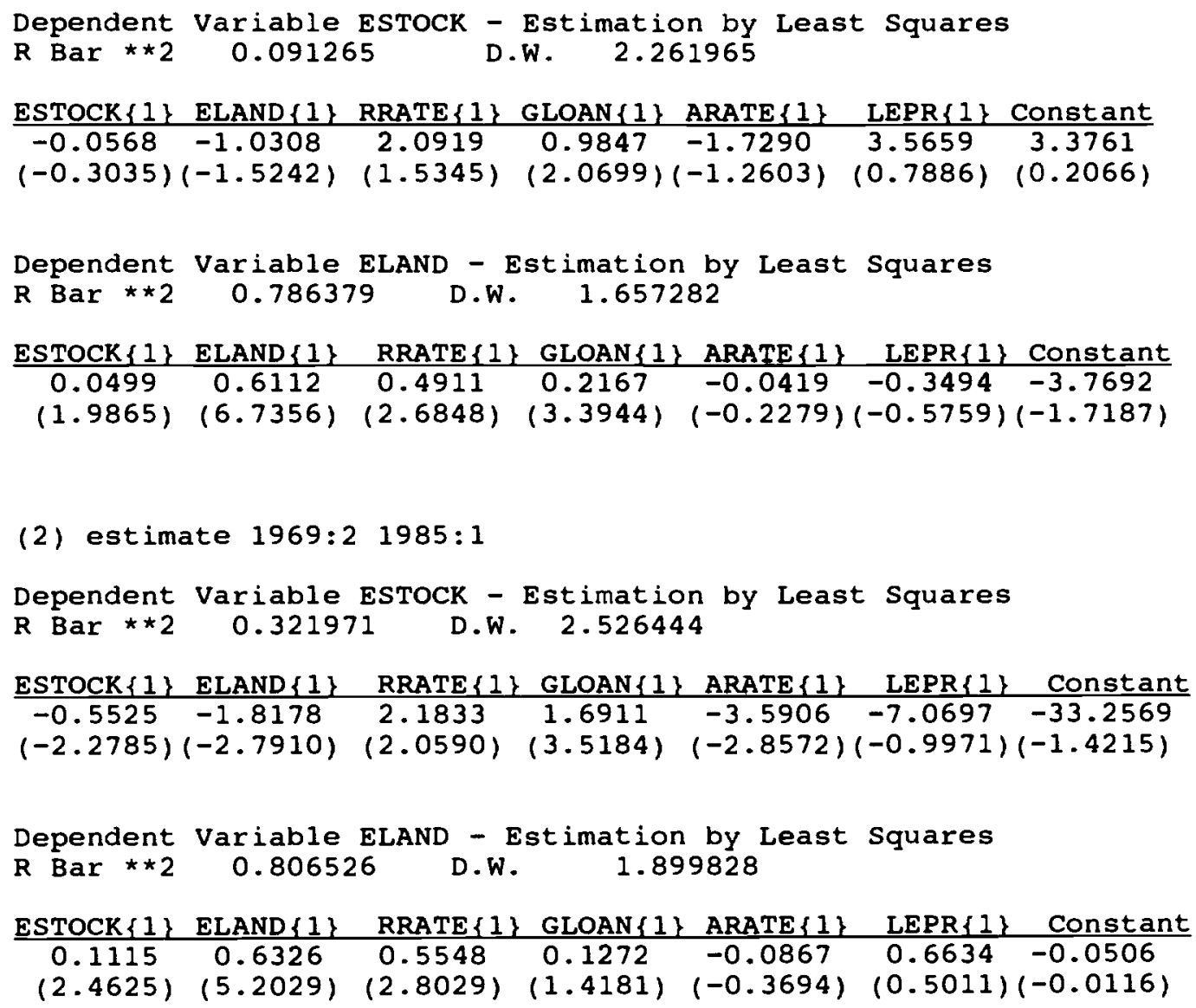




\section{Table 4.2 Granger Causality Tests}

Note: F-statistics. Significance levels in parentheses.

(1) Estimate 1969:2-1993:1

Variable

\begin{tabular}{|c|c|c|c|c|c|c|}
\hline & ESTOCK & ELAND & RRATE & GLOAN & ARATE & LEPR \\
\hline \multicolumn{7}{|l|}{ From: } \\
\hline ESTOCK & {$\left[\begin{array}{l}0.0921 \\
{[0.7631]}\end{array}\right.$} & $\begin{array}{c}3.9462 \\
{[0.0537]}\end{array}$ & $\begin{array}{c}0.2777 \\
{[0.6011]}\end{array}$ & $\begin{array}{c}0.0261 \\
{[0.8725]}\end{array}$ & $\begin{array}{c}0.2777 \\
{[0.6011]}\end{array}$ & $\begin{array}{c}1.3922 \\
{[0.2448]}\end{array}$ \\
\hline ELAND & $\begin{array}{c}2.3231 \\
{[0.1351]}\end{array}$ & $\begin{array}{l}45.3678 \\
{[0.0000]}\end{array}$ & $\begin{array}{c}1.8663 \\
{[0.1793]}\end{array}$ & $\begin{array}{c}0.0160 \\
{[0.8999]}\end{array}$ & $\begin{array}{c}1.8663 \\
{[0.1793]}\end{array}$ & $\begin{array}{l}11.4188 \\
{[0.0016]}\end{array}$ \\
\hline RRATE & $\begin{array}{c}2.3546 \\
{[0.1326]}\end{array}$ & $\begin{array}{c}7.2083 \\
{[0.0104]}\end{array}$ & $\begin{array}{l}10.2560 \\
{[0.0026]}\end{array}$ & {$\left[\begin{array}{l}3.0146 \\
{[0.0900]}\end{array}\right.$} & $\begin{array}{l}12.9077 \\
{[0.0009]}\end{array}$ & $\begin{array}{c}1.3468 \\
{[0.2526]}\end{array}$ \\
\hline GLOAN & $\begin{array}{c}4.2847 \\
{[0.0448]}\end{array}$ & $\begin{array}{l}11.5218 \\
{[0.0015]}\end{array}$ & $\begin{array}{c}0.7215 \\
{[0.4006]}\end{array}$ & $\begin{array}{l}20.5922 \\
{[0.0000]}\end{array}$ & $\begin{array}{c}0.7215 \\
{[0.4006]}\end{array}$ & $\begin{array}{c}8.3870 \\
{[0.0060]}\end{array}$ \\
\hline ARATE & $\begin{array}{c}1.5883 \\
{[0.2147]}\end{array}$ & $\begin{array}{c}0.0519 \\
{[0.8209]}\end{array}$ & $\begin{array}{c}1.1944 \\
{[0.2808]}\end{array}$ & $\begin{array}{c}0.6692 \\
{[0.4181]}\end{array}$ & $\begin{array}{c}1.1944 \\
{[0.2808]}\end{array}$ & $\begin{array}{c}0.7523 \\
{[0.3908]}\end{array}$ \\
\hline LEPR & {$\left[\begin{array}{c}0.6219 \\
{[0.4349]}\end{array}\right.$} & $\begin{array}{c}0.3317 \\
{[0.5678]}\end{array}$ & $\begin{array}{c}0.5305 \\
{[0.4706]}\end{array}$ & $\begin{array}{c}4.8521 \\
{[0.0333]}\end{array}$ & $\begin{array}{c}0.5305 \\
{[0.4706]}\end{array}$ & $\begin{array}{l}352.9417 \\
{[0.0000]}\end{array}$ \\
\hline
\end{tabular}

(2) Estimate 1969:2-1985:1

F-Tests, Dependent Variable ESTOCK

\begin{tabular}{|c|c|c|c|c|c|c|}
\hline & ESTOCK & ELAND & RRATE & GLOAN & ARATE & LEPR \\
\hline \multicolumn{7}{|l|}{ From: } \\
\hline ESTOCK & {$\left[\begin{array}{c}5.1914 \\
{[0.0315]}\end{array}\right.$} & $\begin{array}{c}6.0637 \\
{[0.0210]}\end{array}$ & $\begin{array}{c}0.4608 \\
{[0.5035]}\end{array}$ & $\begin{array}{c}0.0847 \\
{[0.7734]}\end{array}$ & $\begin{array}{c}0.4608 \\
{[0.5035]}\end{array}$ & $\begin{array}{c}2.7043 \\
{[0.1126]}\end{array}$ \\
\hline ELAND & $\begin{array}{c}7.7895 \\
{[0.0099]}\end{array}$ & $\begin{array}{l}27.0702 \\
{[0.0000]}\end{array}$ & $\begin{array}{c}1.3708 \\
{[0.2527]}\end{array}$ & $\begin{array}{c}0.2313 \\
{[0.6348]}\end{array}$ & $\begin{array}{c}1.3708 \\
{[0.2527]}\end{array}$ & $\begin{array}{l}18.4632 \\
{[0.0002]}\end{array}$ \\
\hline RRATE & $\begin{array}{c}4.2394 \\
{[0.0501]}\end{array}$ & $\begin{array}{c}7.8560 \\
{[0.0096]}\end{array}$ & $\begin{array}{c}8.8560 \\
{[0.0064]}\end{array}$ & $\begin{array}{c}2.5806 \\
{[0.1207]}\end{array}$ & $\begin{array}{l}10.5339 \\
{[0.0033]}\end{array}$ & $\begin{array}{c}1.7588 \\
{[0.1968]}\end{array}$ \\
\hline GLOAN & $\begin{array}{l}12.3788 \\
{[0.0017]}\end{array}$ & $\begin{array}{c}2.0109 \\
{[0.1685]}\end{array}$ & $\begin{array}{c}0.8671 \\
{[0.3607]}\end{array}$ & $\begin{array}{l}12.6155 \\
{[0.0016]}\end{array}$ & $\begin{array}{c}0.8671 \\
{[0.3607]}\end{array}$ & $\begin{array}{c}9.8311 \\
{[0.0044]}\end{array}$ \\
\hline ARATE & $\begin{array}{c}8.1637 \\
{[0.0085]}\end{array}$ & $\begin{array}{c}0.1365 \\
{[0.7149]}\end{array}$ & $\begin{array}{c}0.0038 \\
{[0.9511]}\end{array}$ & {$\left[\begin{array}{c}1.6441 \\
{[0.2115]}\end{array}\right.$} & $\begin{array}{c}0.0038 \\
{[0.9511]}\end{array}$ & $\begin{array}{c}4.9941 \\
{[0.0346]}\end{array}$ \\
\hline LEPR & $\begin{array}{c}0.9941 \\
{[0.3283]}\end{array}$ & {$\left[\begin{array}{c}0.2511 \\
{[0.6207]}\end{array}\right.$} & $\begin{array}{c}0.4725 \\
{[0.4982]}\end{array}$ & $\begin{array}{c}3.7951 \\
{[0.0627]}\end{array}$ & $\begin{array}{c}0.4725 \\
{[0.4981]}\end{array}$ & $\begin{array}{l}114.0187 \\
{[0.0000]}\end{array}$ \\
\hline
\end{tabular}




\section{Table 4.3: Variance Decomposition for Asset Prices}

Eu: Unexpected excess return.

Ed: News about future dividends/rents.

Er: News about future real interest rates.

Ee: News about future excess returns.

(S-1) Covariance $\backslash$ Correlation Matrix of Stock Returns

(a) full sample, 69:2-93:1

\begin{tabular}{lrrrr} 
Eu & 157.7809 & \multicolumn{1}{c}{ Ec } & Er & \multicolumn{1}{c}{ Ee } \\
Ec & 91.8068 & 101.5252 & 0.0729 & -0.5869 \\
Er & 2.9973 & 2.4518 & 10.7030 & -0.3675 \\
Ee & -68.9714 & 7.3211 & -11.2485 & 87.5410
\end{tabular}

(b) sub sample, 69:2-85:1

\begin{tabular}{lrrrr} 
& Eu & Ec & Er & \multicolumn{1}{c}{ Ee } \\
Eu & 81.1310 & 0.6932 & -0.2401 & -0.5059 \\
Ec & 50.6758 & 65.8698 & 0.2850 & 0.1959 \\
Er & -6.3395 & 6.7815 & 8.5962 & 0.2916 \\
Ee & -24.1158 & 8.4125 & 4.5248 & 28.0035
\end{tabular}

(s-2) Variance Decomposition for stock Returns

\begin{tabular}{crr} 
Sample Period & $69: 2-93: 1$ & $69: 2-85: 1$ \\
\hline shares of & 0.6438 & 0.8119 \\
$\operatorname{var}$ Ec & -0.0311 & -0.1672 \\
$-2 \operatorname{cov}(E c, E r)$ & -0.0928 & -0.2074 \\
$-2 \operatorname{cov}(E c, E e)$ & 0.0678 & 0.1060 \\
$\operatorname{var} \operatorname{Er}$ & -0.1426 & 0.1115 \\
$2 \operatorname{cov}(\mathrm{Er}$, Ee) & 0.5548 & 0.3452 \\
$\operatorname{var}$ Ee &
\end{tabular}

(L-1) CovariancelCorrelation Matrix of Land Capital Gains

(a) full sample, 69:2-93:1

\begin{tabular}{lrrrr} 
& Eu & Ec & Er & \multicolumn{1}{c}{ Ee } \\
Eu & 2.8405 & 0.2117 & -0.7467 & 0.3321 \\
Ec & 2.1971 & 37.9129 & 0.0075 & 0.9306 \\
Er & -4.1174 & 0.1508 & 10.7030 & -0.3169 \\
Ee & 3.4739 & 35.5650 & -6.4348 & 38.5259
\end{tabular}

(b) sub sample, 69:2-85:1

\begin{tabular}{lrrrr} 
& Eu & Ec & Er & \multicolumn{1}{c}{ Ee } \\
Eu & 2.8274 & 0.3617 & -0.8704 & 0.4591 \\
Ec & 4.5238 & 55.3294 & -0.2528 & 0.9762 \\
Er & -4.2913 & -5.5123 & 8.5962 & -0.4317 \\
Ee & 5.9877 & 56.3179 & -9.8172 & 60.1474
\end{tabular}

(s-2) Variance Decomposition for stock Returns

\begin{tabular}{lrr} 
Sample Period & $69: 2-93: 1$ & $69: 2-85: 1$ \\
\hline shares of & 13.3471 & 19.5687 \\
$\operatorname{var}$ Ec & -0.1062 & 3.8991 \\
$-2 \operatorname{cov}(\mathrm{EC}, \mathrm{Er})$ & -25.0411 & -39.8366 \\
$-2 \operatorname{cov}(\mathrm{Ec}, \mathrm{Ee})$ & 3.7680 & 3.0403 \\
$\operatorname{var} \mathrm{Er}$ & -4.5307 & -6.9442 \\
$2 \operatorname{cov}(\mathrm{Er}, \mathrm{Ee})$ & 13.5629 & 21.2727 \\
$\operatorname{var}$ Ee &
\end{tabular}

The numbers above the diagonal (shown in bold face) in covariance matrix are correlations. 


\section{Table 5.1 : Determinants of Land Price}

Semi-Annual Data From 1969:01 To 1993:01

Dependent Variable : GLAND(Growth Rate of Real Land Price)

note:

(i) t-statistics in parentheses

(ii) Definition of Variables:

GGNP: Growth Rate of Real GNP

ARATE: Interest Rate (Call Rate) Change from the Previous Period

INFL: Inflation Rate (Measured by GNP Deflator)

GLOAN: Growth Rate of Outstanding Real Bank Loan to Real Estate Sectors

(iii) S.Sq.R. = Sum of Squared Residuals

\begin{tabular}{|c|c|c|c|c|c|c|c|}
\hline (1) & 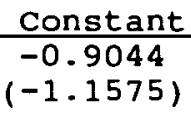 & $\begin{array}{c}\text { GGNP } \\
0.9283 \\
(3.8781)\end{array}$ & $\begin{array}{c}\text { GLOAN } \\
0.1934 \\
(3.1818)\end{array}$ & $\begin{array}{c}\text { ARATE } \\
0.9119 \\
(3.5314)\end{array}$ & $\begin{array}{c}\text { INFL } \\
-0.4144 \\
(-2.3472)\end{array}$ & $\begin{array}{l}\text { R Bar } \star \star 2 \\
\text { D.W. } \\
\text { S.Sq.R. }\end{array}$ & $\begin{array}{r}0.5584 \\
1.5231 \\
282.8015\end{array}$ \\
\hline (2) & Constant & GGNP & GLOAN & GMONEY & INFL & Bar $* \star 2$ & \\
\hline & $\begin{array}{c}-2.0987 \\
(-2.2933)\end{array}$ & $\begin{array}{c}0.8009 \\
(2.7776)\end{array}$ & $\begin{array}{c}0.0708 \\
(0.8725)\end{array}$ & $\begin{array}{c}0.4490 \\
(2.1467)\end{array}$ & $\begin{array}{l}-0.1071 \\
(-0.5296)\end{array}$ & $\begin{array}{l}\text { D.W. } \\
\text { S.Sg.R. }\end{array}$ & $\begin{array}{r}1.009 \\
336.415\end{array}$ \\
\hline
\end{tabular}

\begin{tabular}{|c|c|c|c|c|c|c|c|}
\hline Constant & GLAND & GGNP & GLOAN & ARATE & INFL & & \\
\hline $\begin{array}{l}-1.1500 \\
(-1.9532)\end{array}$ & & $\begin{array}{c}0.3299 \\
(1.7121)\end{array}$ & $\begin{array}{l}-0.0186 \\
(-0.3255)\end{array}$ & $\begin{array}{c}0.0272 \\
(0.1239)\end{array}$ & $\begin{array}{l}-0.9894 \\
(-4.9845)\end{array}$ & $\begin{array}{l}\text { R Bar } \\
\text { D.W. }\end{array}$ & $\begin{array}{l}0.7967 \\
1.6300\end{array}$ \\
\hline 11 ag & $\begin{array}{c}0.4740 \\
(4.1380)\end{array}$ & $\begin{array}{c}0.4165 \\
(2.0662)\end{array}$ & $\begin{array}{c}0.2123 \\
(3.6851)\end{array}$ & $\begin{array}{c}0.2370 \\
(1.0959)\end{array}$ & $\begin{array}{c}0.4707 \\
(2.4084)\end{array}$ & S.Sq.R. & 115.4169 \\
\hline
\end{tabular}

\begin{tabular}{cccccccrr} 
(4) Constant & GLAND & GGNP & GLOAN & GMONEY & INFL & & \\
\cline { 1 - 5 }$(-1.7486$ & & 0.0676 & -0.0894 & 0.3711 & -0.7876 & R Bar $* \star 2$ & 0.8296 \\
$(-3.0142)$ & & $(0.3546)$ & $(-1.6179)$ & $(2.1467)(-3.6143)$ & D.W. & 2.0169 \\
$1 \mathrm{lag}$ & 0.5330 & 0.3649 & 0.1553 & 0.1178 & 0.4489 & S.Sq.R. & 96.7461 \\
& $(5.7834)$ & $(1.9658)$ & $(2.7657)$ & $(0.6691)$ & $(2.1643)$ & & &
\end{tabular}




\section{Table 5.2 : Determinants of Bank Loans to Real Estate Companies}

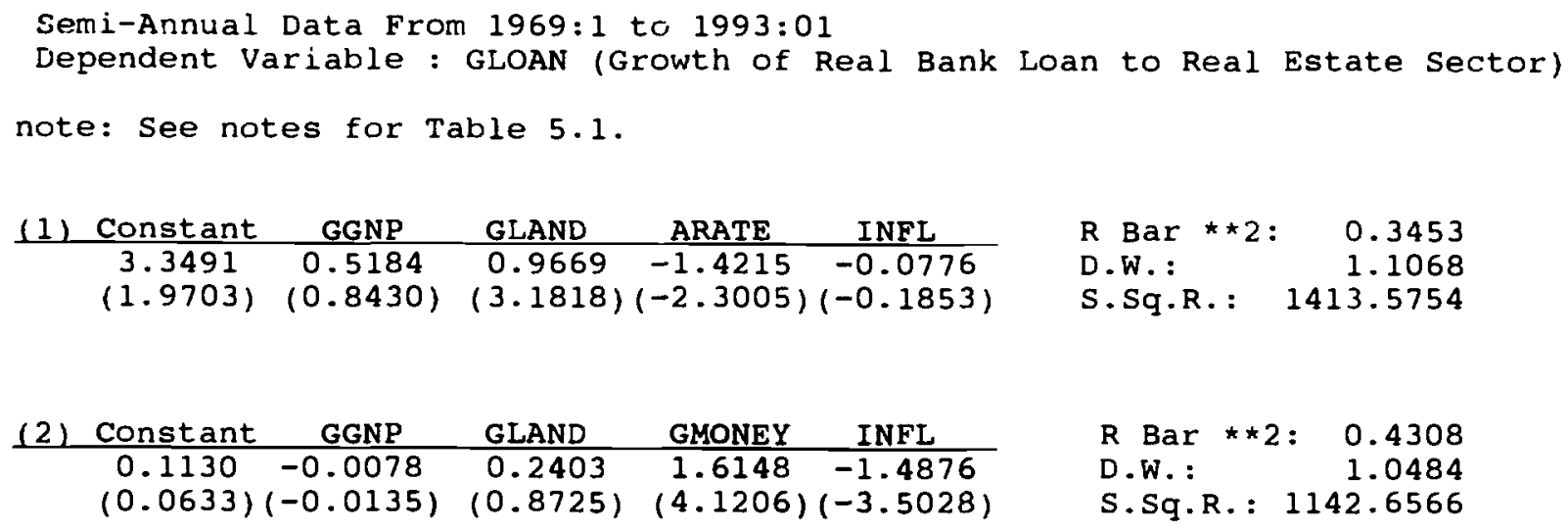




\section{Table 5.3: Bivariate VAR(1); GLAND and GLOAN}

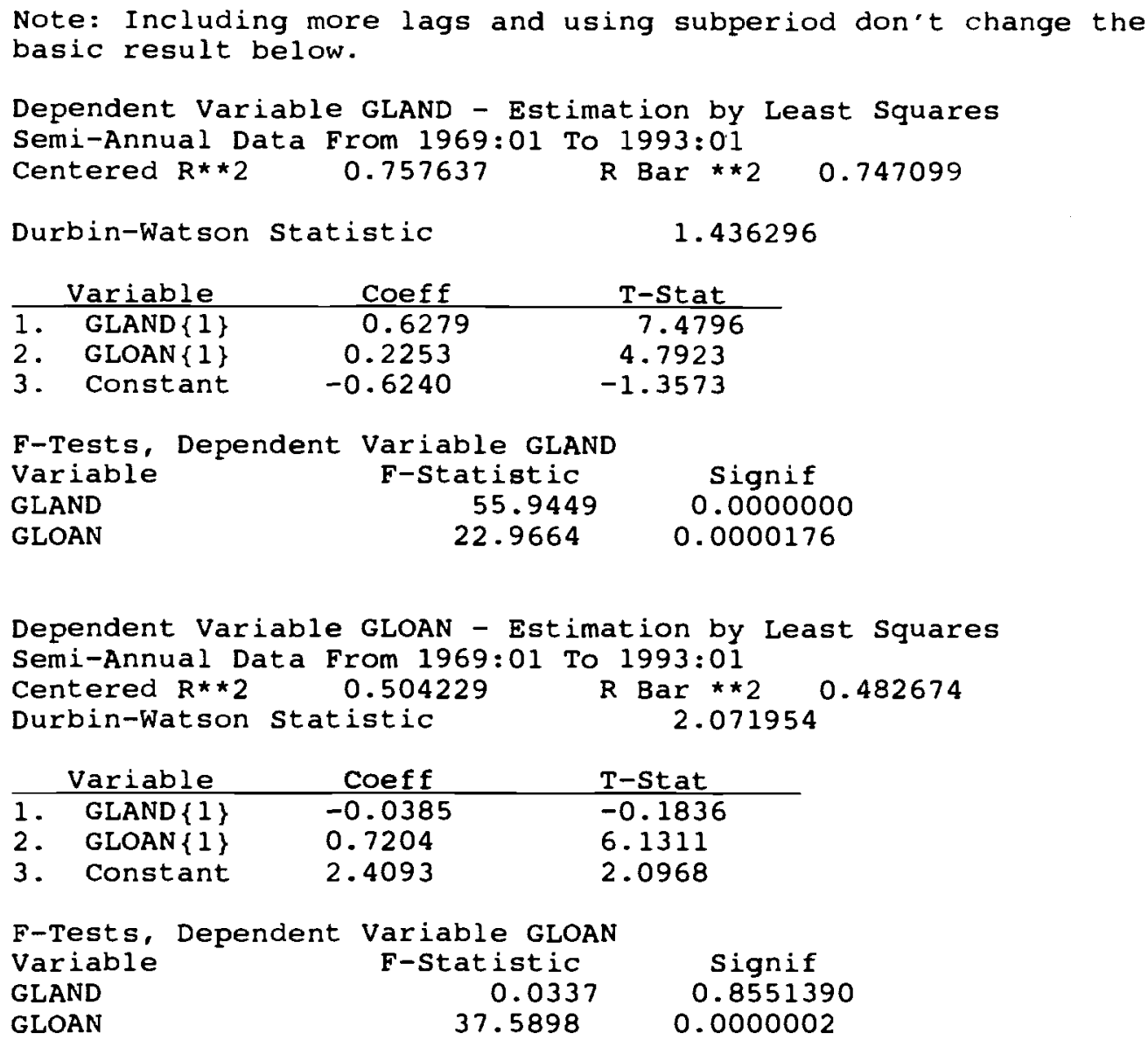




\section{Figure 2.1: Stock and Land Prices}

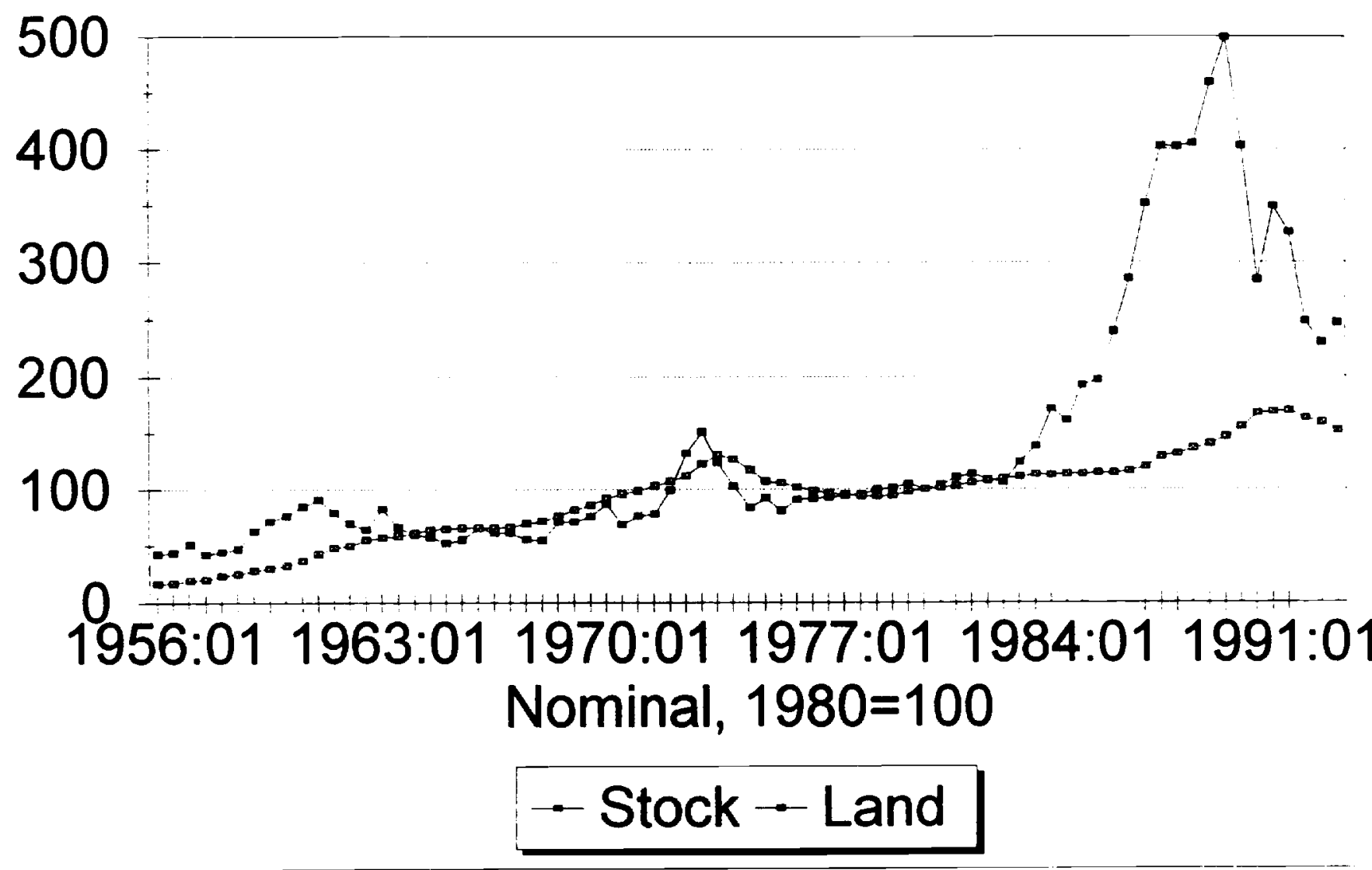


Figure 2.2: Asset Price Growth Rates

(\%) 40

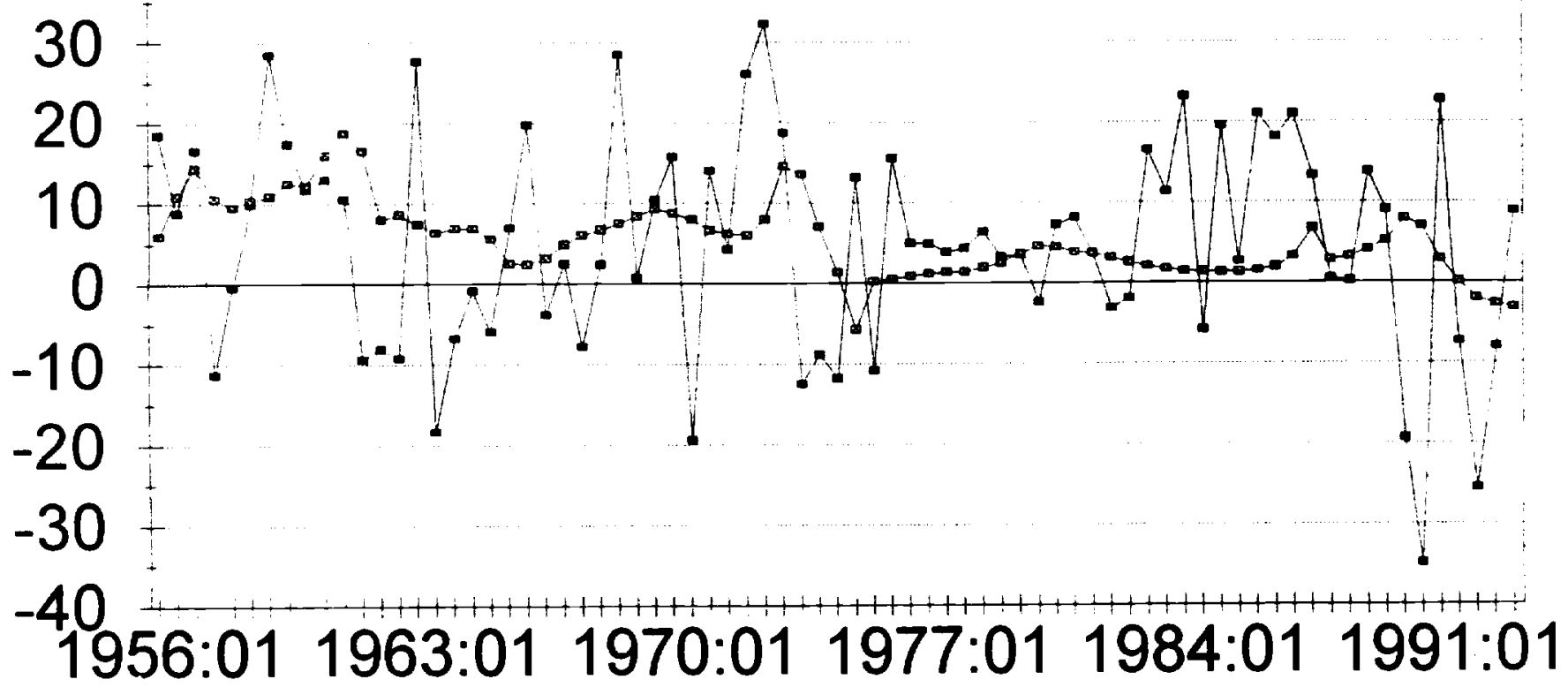

Nominal Growth Rates

$\rightarrow$ Stock - Land 
Figure 2.3 (a) Responses in returns

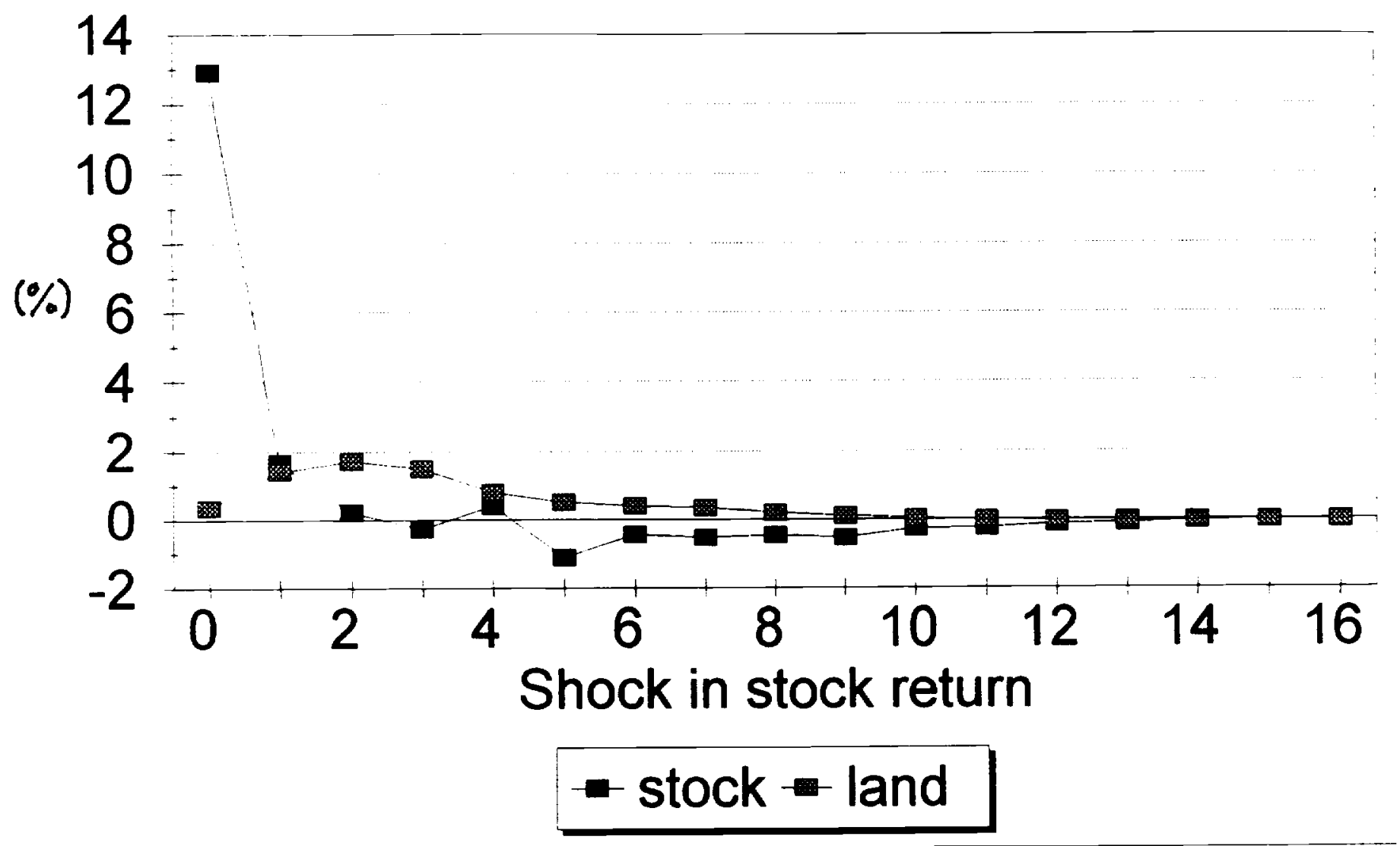


Figure 2.3 (b) Responses in returns

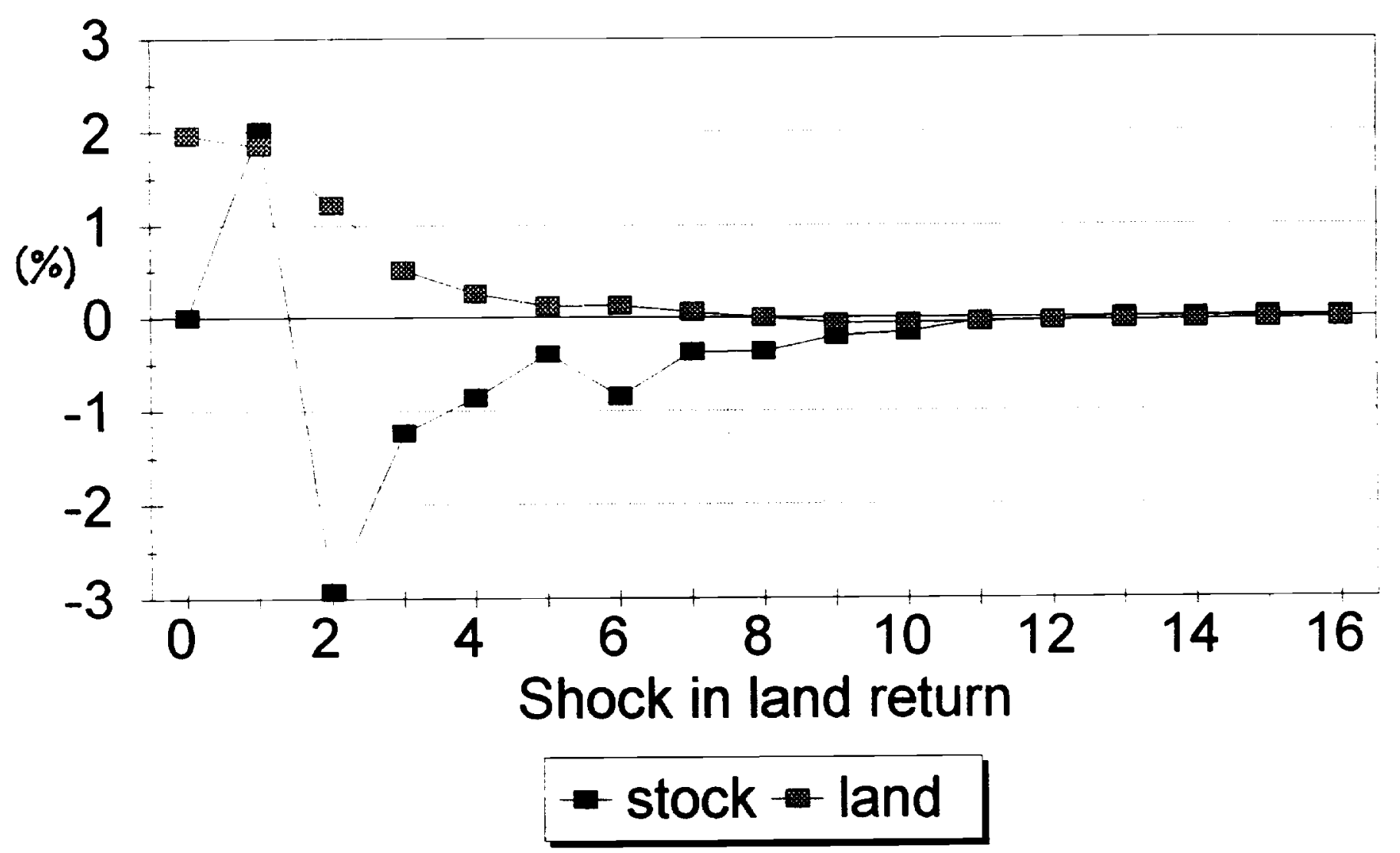




\section{Figure 2.4 (a) Responses in level}

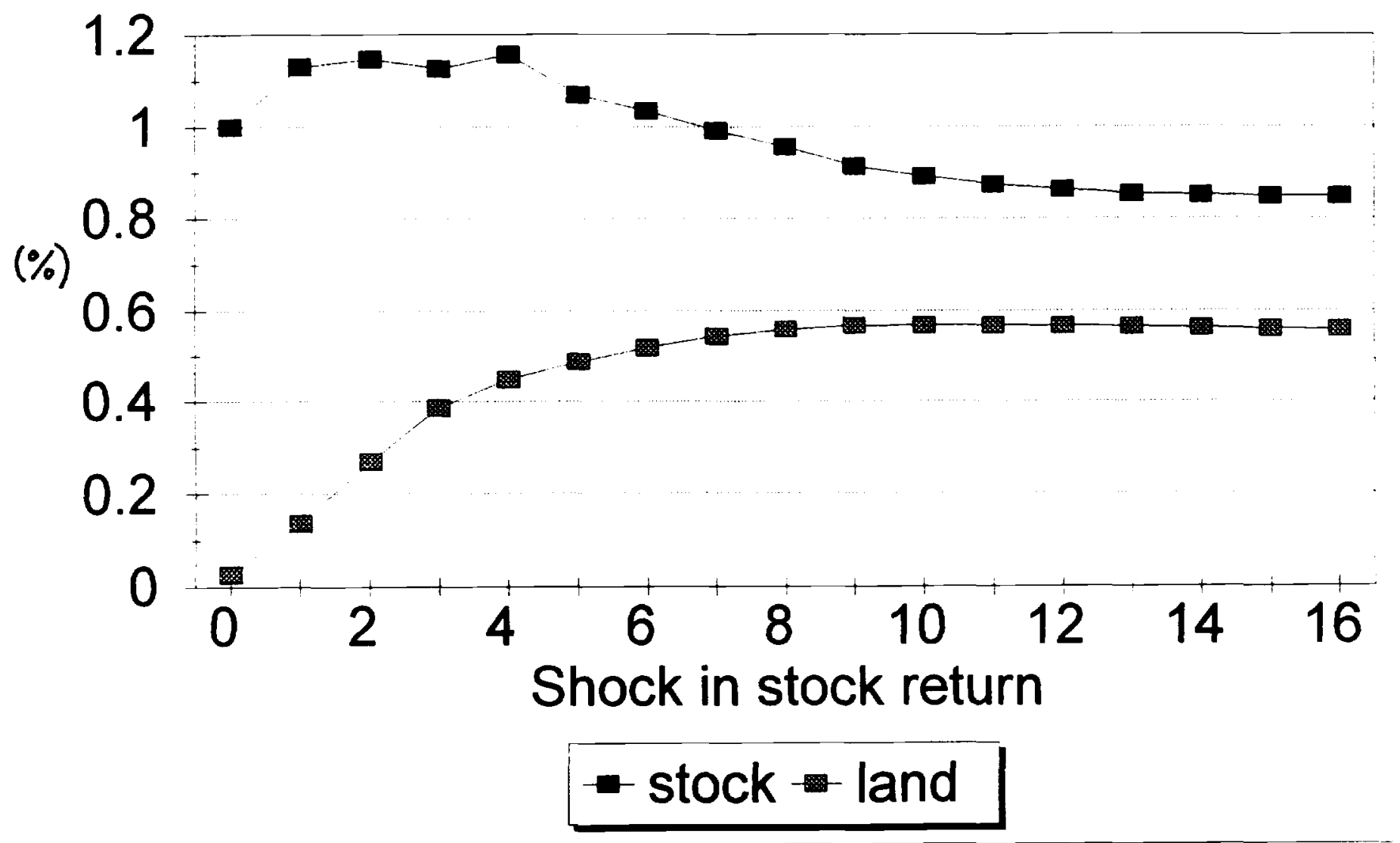

Note: Impulse responses are calculated in excess returns (Figure 2.3), then transformed into the level (Figure 2.4). Figure 2.4 shows the changes in level (\%). 
Figure 2.4 (b) Responses in level

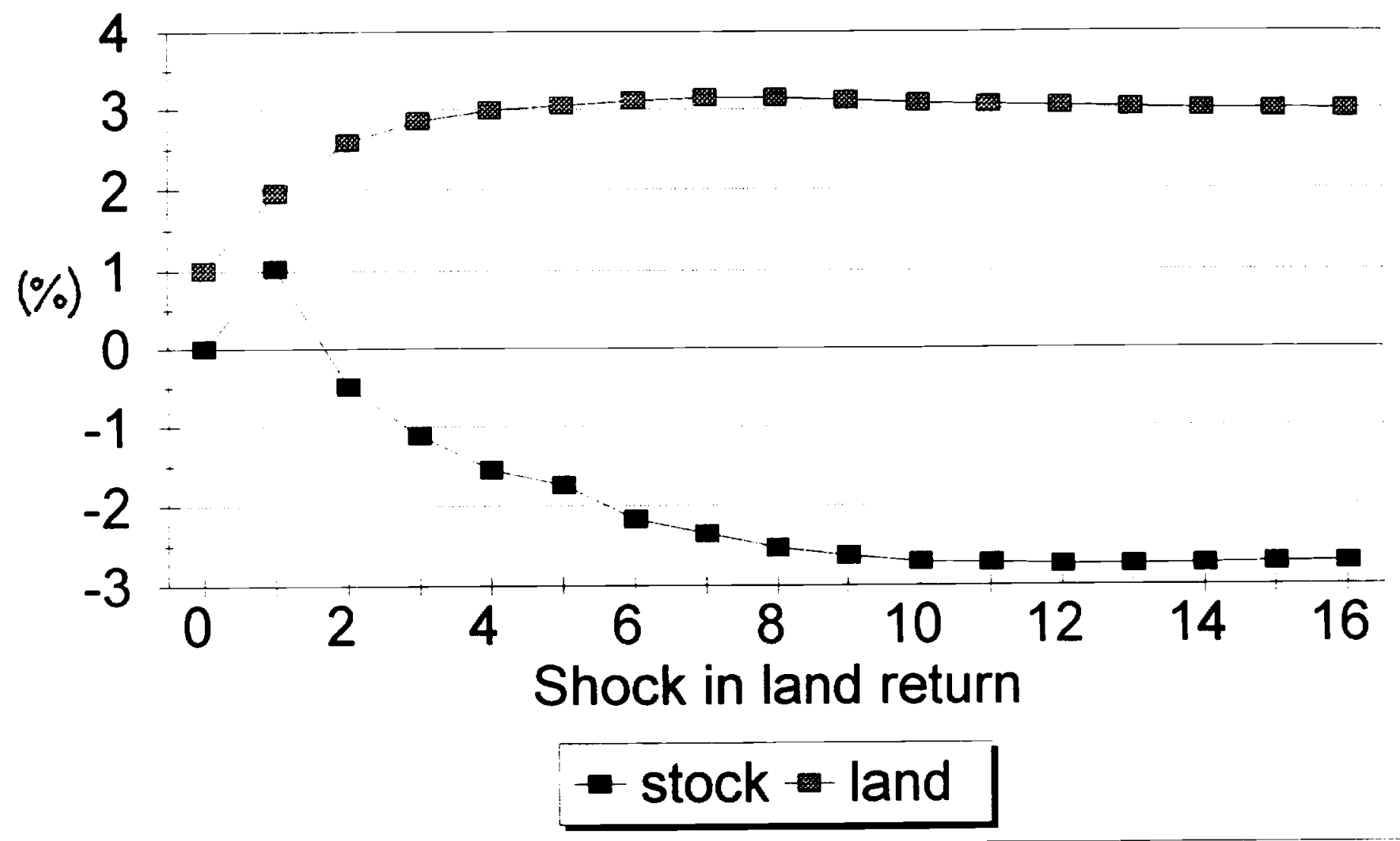




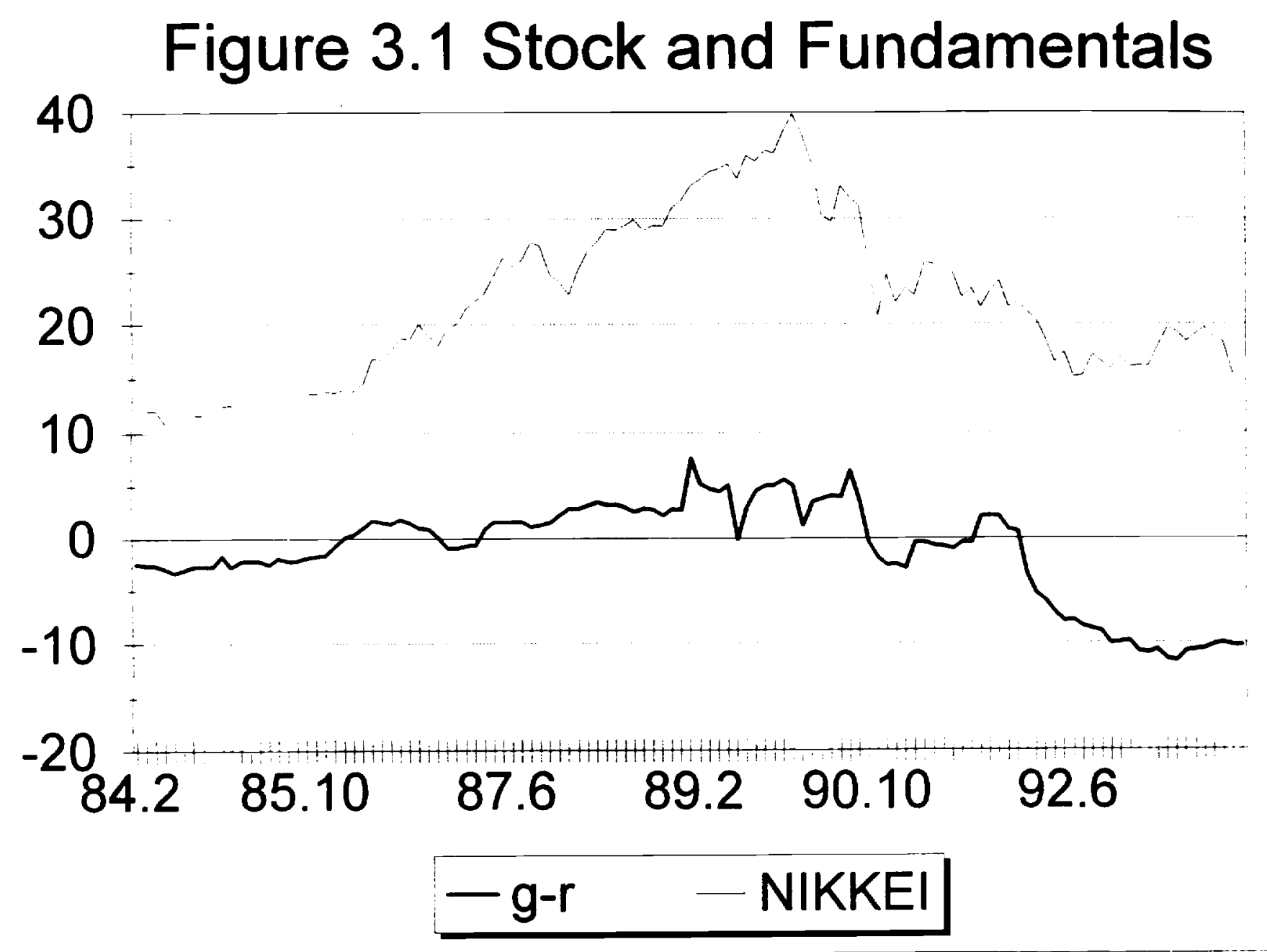


Figure 3.2 Sample bubble pathes

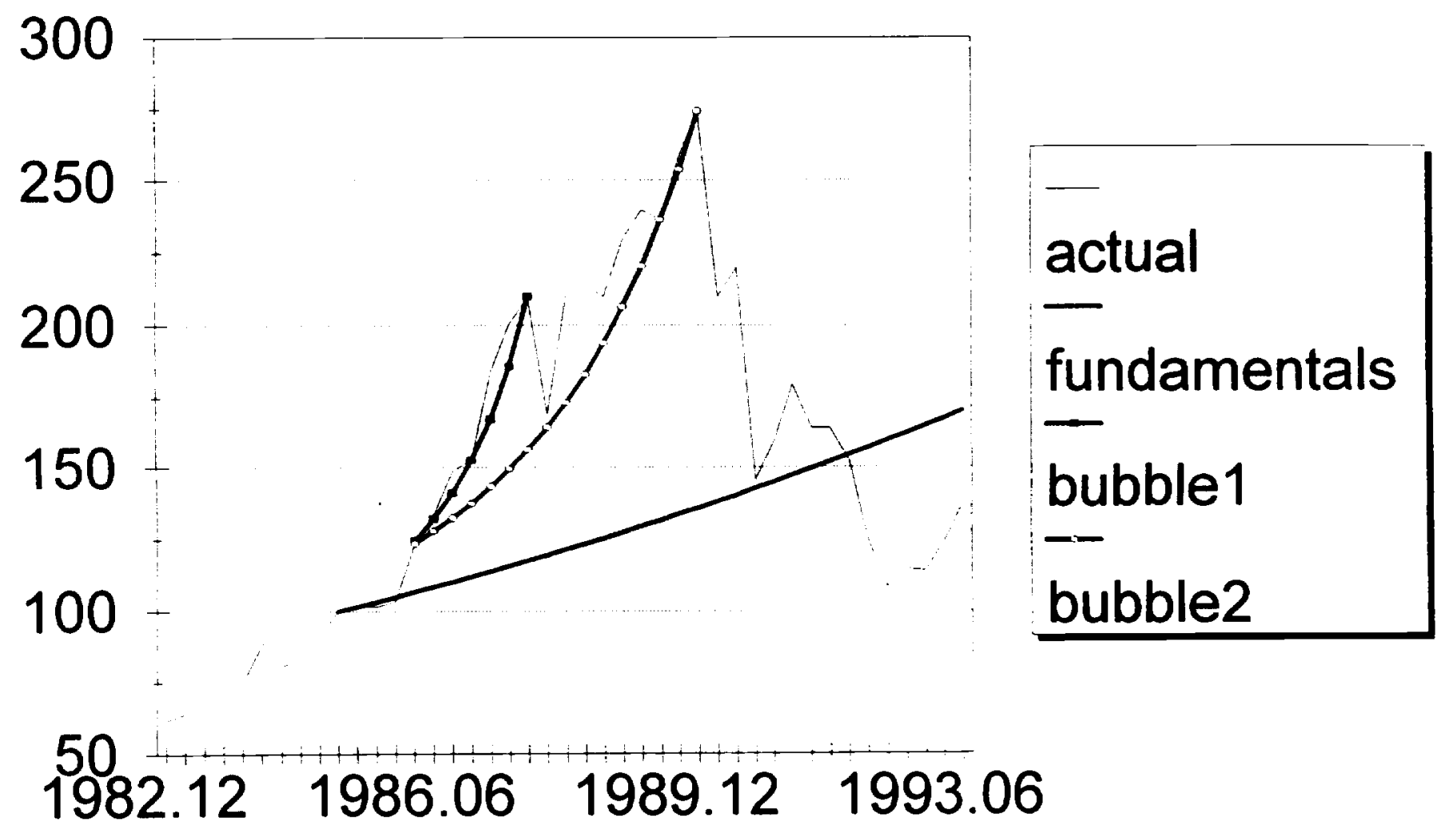




\section{Figure 3.3: Term Structure, 84:1-93:1}

10

(\%) 6

4

$2-$

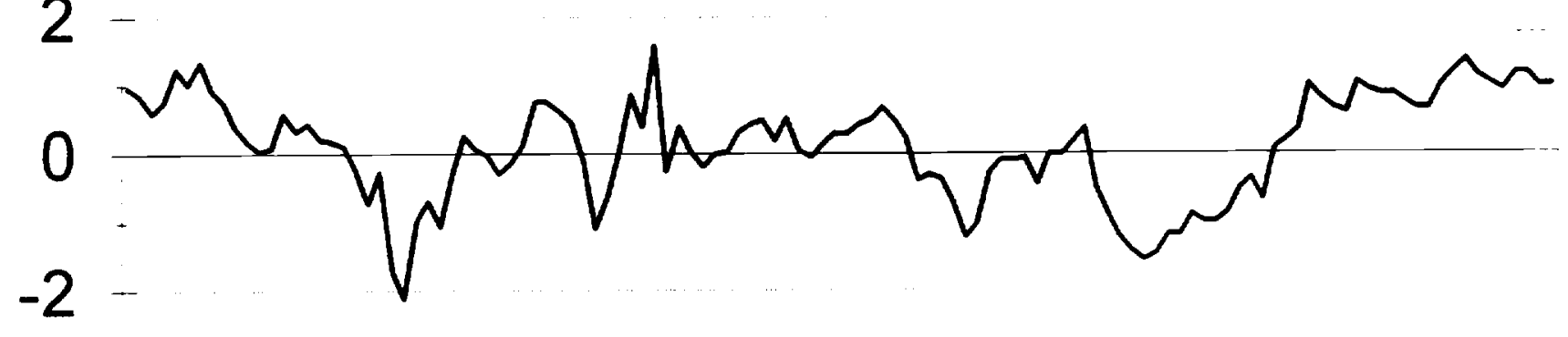

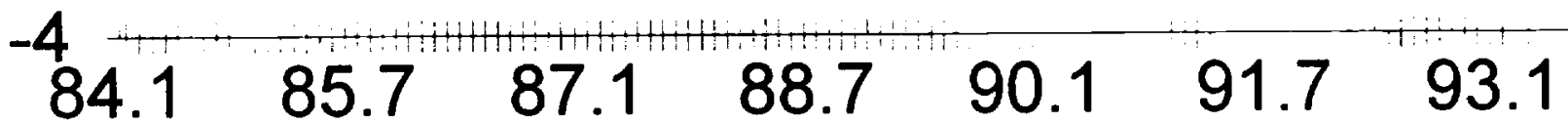

- spread -..-discount - short 
Figure 3.4: Real Interest Rate

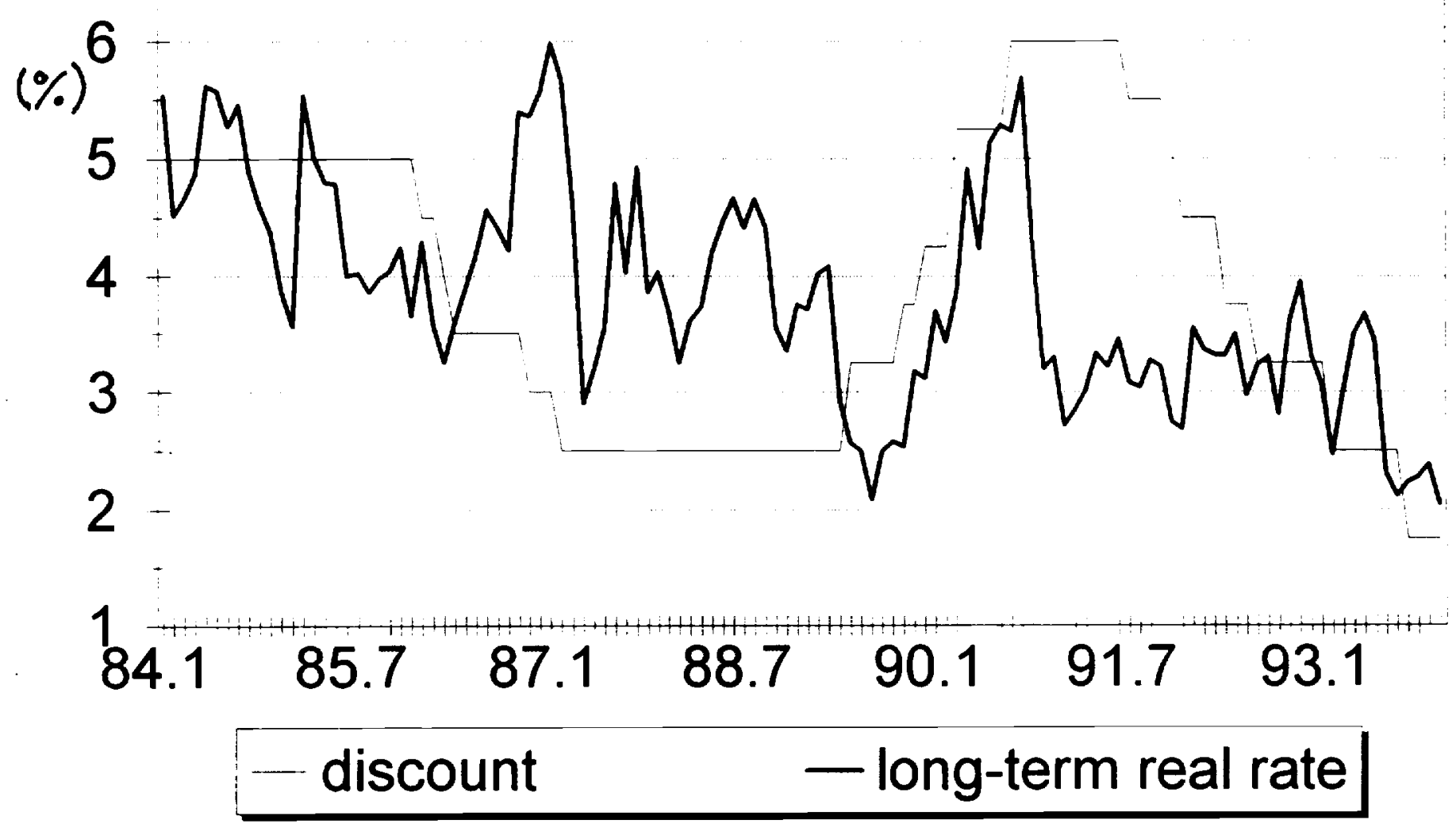




\section{Figure 4.1: Unexpected Excess Return and Future Excess Return}

Eu: Unexpected Excess Return

Ee: Future Excess Return

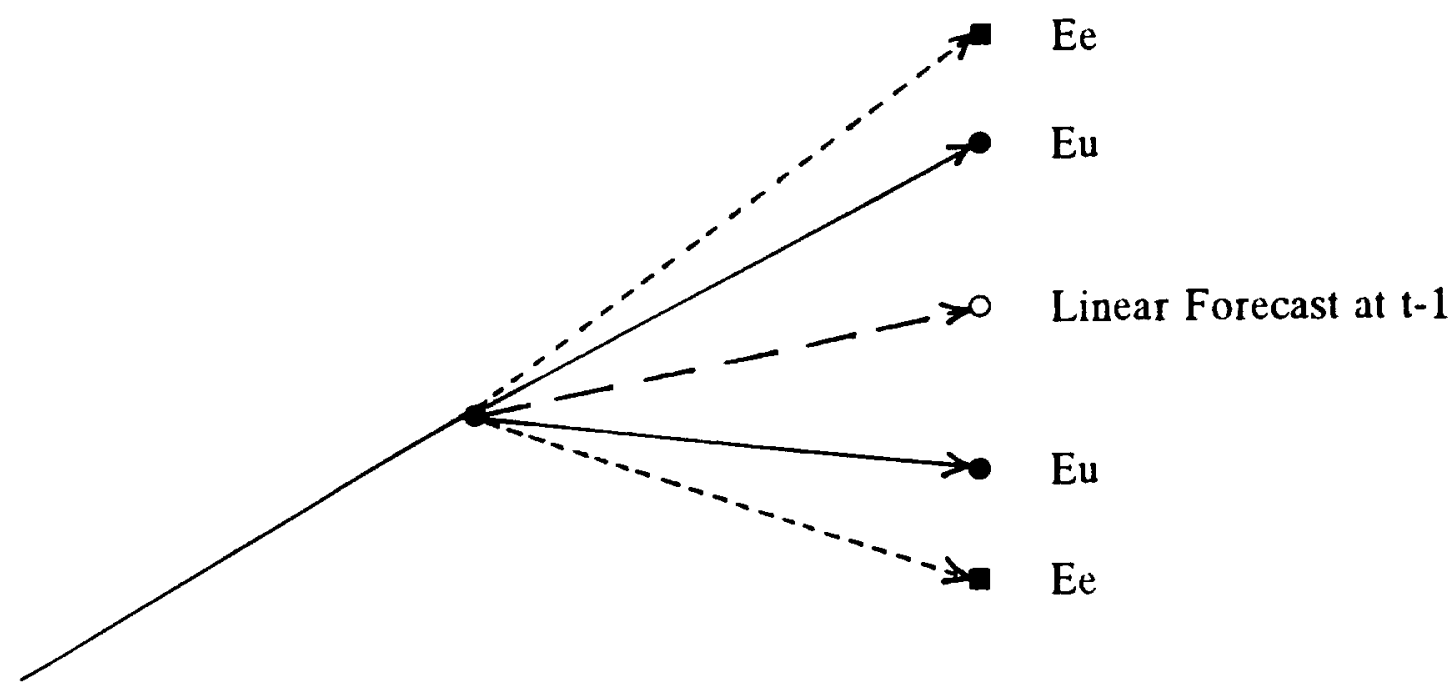

$t-1$ 
Figure 5.1 Land Price and the Debt of the Firm

$$
\begin{aligned}
& \mathrm{q}=\text { Land Price, } \quad \mathrm{B}=\text { Debt, } \\
& \mathrm{X}^{*}=\text { Steady State Value of the variable } \mathrm{X}
\end{aligned}
$$

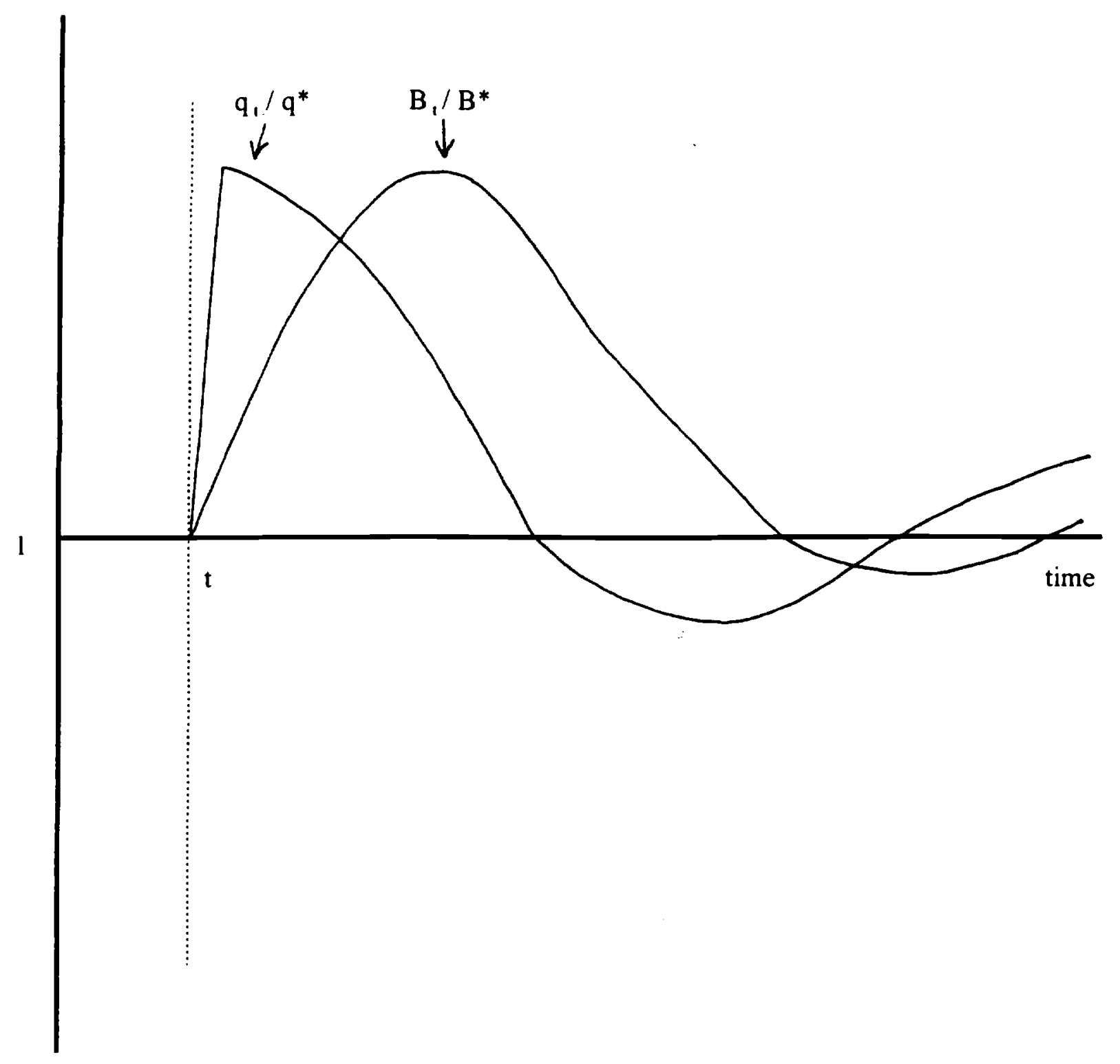

Reference: Kiyotaki and Moore (1995) 


\section{Figure 5.2: Bank Lending and Land Price}

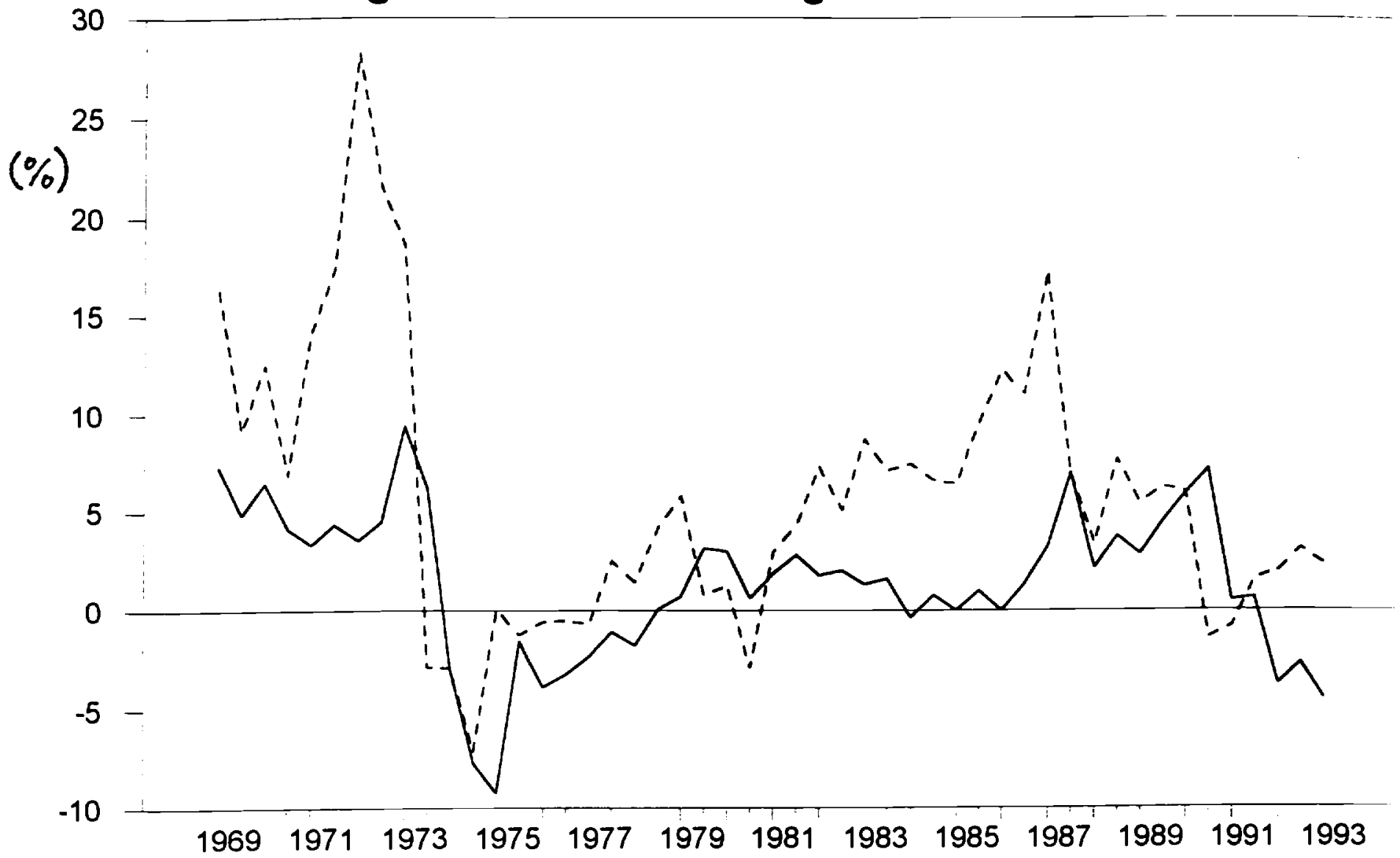

$-\quad:$ Growth Rate of Land Price

: Growth of Bank Lending to the Real Estate Sector

Note: Both variables are in real term. 